IZA DP No. 10275

The Gain from the Drain:

Skill-biased Migration and Global Welfare

Costanza Biavaschi

Michał Burzyński

Benjamin Elsner

Joël Machado

October 2016 


\title{
The Gain from the Drain: Skill-biased Migration and Global Welfare
}

\author{
Costanza Biavaschi \\ University of Reading and IZA
}

\author{
Michał Burzyński \\ University of Luxembourg
}

\section{Benjamin Elsner}

IZA and CReAM

Joël Machado

University of Luxembourg

\section{Discussion Paper No. 10275 \\ October 2016}

\author{
IZA \\ P.O. Box 7240 \\ 53072 Bonn \\ Germany \\ Phone: +49-228-3894-0 \\ Fax: +49-228-3894-180 \\ E-mail: iza@iza.org
}

\begin{abstract}
Any opinions expressed here are those of the author(s) and not those of IZA. Research published in this series may include views on policy, but the institute itself takes no institutional policy positions. The IZA research network is committed to the IZA Guiding Principles of Research Integrity.

The Institute for the Study of Labor (IZA) in Bonn is a local and virtual international research center and a place of communication between science, politics and business. IZA is an independent nonprofit organization supported by Deutsche Post Foundation. The center is associated with the University of Bonn and offers a stimulating research environment through its international network, workshops and conferences, data service, project support, research visits and doctoral program. IZA engages in (i) original and internationally competitive research in all fields of labor economics, (ii) development of policy concepts, and (iii) dissemination of research results and concepts to the interested public.
\end{abstract}

IZA Discussion Papers often represent preliminary work and are circulated to encourage discussion. Citation of such a paper should account for its provisional character. A revised version may be available directly from the author. 


\section{ABSTRACT \\ The Gain from the Drain: Skill-biased Migration and Global Welfare*}

High-skilled workers are four times more likely to migrate than low-skilled workers. This skill bias in migration - often called brain drain - has been at the center of a heated debate about the welfare consequences of emigration from developing countries. In this paper, we provide a global perspective on the brain drain by jointly quantifying its impact on the sending and receiving countries. In a calibrated multi-country model, we compare the current world to a counterfactual with the same number of migrants, but those migrants are randomly selected from their country of origin. We find that the skill bias in migration significantly increases welfare in most receiving countries. Moreover, due to a more efficient global allocation of talent, the global welfare effect is positive, albeit some sending countries lose. Overall, our findings suggest that more - not less - high-skilled migration would increase world welfare.

JEL Classification: F22, O15, J61

Keywords: migration, brain drain, global welfare

Corresponding author:

Benjamin Elsner

IZA

Schaumburg-Lippe-Str. 5-9

53113 Bonn

Germany

E-mail: elsner@iza.org

\footnotetext{
* We would like to thank George Borjas, Arnaud Chevalier, Michael Clemens, Frédéric Docquier, Zoë Kuehn, Florian Mayneris, Elie Murard, Gianmarco Ottaviano, Hillel Rapoport, Agnese Romiti, Gonzague Vannoorenberghe, Dean Yang, and audiences at IZA, OECD, U Luxembourg, U Reading, $U$ Mannheim, $U$ Cologne, $U$ Oxford, the IZA Annual Migration Meeting, EALE, and the RWI/RGS migration workshop for helpful discussions.
} 


\section{INTRODUCTION}

High-skilled workers from developing countries are four times more likely to emigrate than lowskilled workers. ${ }^{1}$ This skill bias in migration — often called 'brain drain' - has been at the center of a controversial debate about the welfare consequences of migration. The popular argument is that rich countries siphon off the best and brightest workers, thereby harming the economic development of poorer countries. Recent literature has challenged this view, showing that sending countries may benefit from high-skilled emigration through incentives to invest in human capital, remittances, technology diffusion, as well as the transfer of social norms and institutions. ${ }^{2}$ However, while a significant body of research has focused on the impact of skill-biased migration in the sending countries, little is known about its impact in the receiving countries. Moreover, if receiving countries gain from skill-biased migration while sending countries lose, the net effect on world welfare remains unclear.

In this paper, we provide a global perspective on the welfare consequences of skill-biased migration. We begin by estimating its impact on the welfare of natives in the receiving countries, and - after taking into account the impact on non-migrants in the sending countries - quantify its impact on global welfare. In a counterfactual analysis, we compare today's world, in which migration is heavily biased towards high-skilled workers, to a world with the same number of migrants but without a skill bias in migration, i.e. a world in which every migrant is randomly selected from his/her country of origin. This strategy isolates the impact of the skill bias from the impact of a change in the scale of migration. Two important results emerge from this analysis. First, most receiving countries significantly gain from skill-biased migration, with particularly large gains in countries with selective immigration policies. Second, the skill bias in migration leads to global welfare gains due to a more efficient allocation of talent between poor and rich countries. In a world with skill-biased migration, a larger number of high-skilled people work in the countries where they are most productive, resulting in global efficiency gains.

To quantify the welfare impact of the skill bias, we develop a general equilibrium model of the world economy, in which countries are linked through trade in differentiated goods. A change in the skills of migrants simultaneously alters the skill composition of the workforce in the sending and receiving countries, which in turn affects welfare through changes in the market size and trade flows. We calibrate the model to match key features of the global economy, namely bilateral trade flows, differences in GDP per capita across countries and wage premia

Own calculations from the 2010 OECD-DIOC database. Docquier \& Rapoport (2012a) find similar figures. Mountford (1997), Stark et al. (1997), Vidal (1998) provide theoretical models showing how high-skilled emigration increases returns to education and triggers investment in human capital in the sending countries. Beine et al. $(2001,2008)$ provide evidence of this effect at the macro level, while case studies by Chand \& Clemens (2008), Batista et al. (2011), Shrestha (2015) and Dinkelman \& Mariotti (2016) provide evidence at the micro level. Evidence on the impact of remittances on stayers in sending countries is provided by Yang (2008), among others. With respect to institutions, Batista \& Vicente (2011) show in a field experiment that return migrants demand better institutions at home, while Mahmoud et al. (2014) show that larger shares of emigrants from Moldova to democratic countries lead to lower vote shares for the communist party. Using panel data for more than 100 countries, Docquier et al. (2015b) show that emigration fosters democratic institutions. For a succinct summary of the most important externalities and a quantification of their importance for developing countries, see Docquier \& Rapoport (2012b). 
for high- and medium-skilled workers within countries. We then use this model to simulate the impact of a change in the skill composition of migrants on natives in the receiving countries and non-migrants in the sending countries. In the simulations, we exogenously change the skill composition of bilateral migrant stocks and compare the welfare of non-migrants in a world with and without skill bias in migration.

The simulations reveal that the skill bias in migration leads to welfare gains between 0 and $2 \%$ among natives in the receiving countries. These gains are largest for countries with selective immigration policies, such as Canada, the UK, the US and Australia. To compute the global welfare effect of skill-biased migration, we perform the same analysis for sending countries. In our baseline simulations, excluding any positive externalities that could offset the welfare losses in the sending countries, we find small welfare losses between 0 and $1 \%$, while in a few countries with a very high skill bias the welfare losses exceed $5 \%$. Taken together, the gains in the receiving countries exceed the losses in the sending countries, resulting in a global welfare gain of about $0.3 \%$.

The global gain of $0.3 \%$ reflects a conservative estimate, as it becomes larger once we account for channels through which high-skilled emigration may benefit the sending countries. In a series of extensions, we include the most important mechanisms highlighted in the literature, such as remittances, network effects in trade, incentives to invest in human capital and a Lucas (1988)type externality, whereby TFP depends on the average level of human capital. Using a wide range of parameters from the empirical literature, we find that most of these channels dampen the losses in the sending countries, resulting in even larger global welfare gains. Among these channels, the brain gain effect - high-skilled emigration triggering higher investment in human capital in the sending countries - is quantitatively most important. Similarly, remittances make a difference for the sending countries.

In a further extension, we use our model to simulate a policy experiment whereby the immigration policy in all OECD countries becomes as selective as in Canada, the country with the most positive selection of immigrants. While such a policy would almost double the global welfare gains, it would also exacerbate the income inequality between sending and receiving countries. Nonetheless, in light of the overall welfare gains, it would be globally optimal to have more skill-biased migration. We also simulate a counterfactual in which the number low-skilled migrants remains constant while the number of high-skilled migrants gets reduced to the point where migration is skill-neutral. Compared to this counterfactual, the average non-migrant in the world is $0.6 \%$ better off in the current world.

This paper contributes to three strands of literature. First, it provides a new perspective on the welfare effects of the brain drain. While the literature thus far has focused on welfare effects in the sending countries, our analysis shows that the brain drain also has important welfare effects in receiving countries and overall increases world welfare. These findings are important for the design and evaluation of migration policies. The focus on the sending countries has led to drastic policy recommendations such as taxing emigrants to compensate the sending countries for their 'loss' in human capital (Bhagwati \& Hamada, 1974), or restricting high-skilled immigration to 
help the sending countries (Collier, 2013). In light of our findings, such policy recommendations would lead to global welfare losses and would be a sub-optimal policy choice if the aim of the policy was to increase global welfare.

Second, this paper contributes to the literature on the self-selection of migrants. A vast number of papers study why migrants are self-selected from their country of origin, i.e. why their skills differ from non-migrants in their country of origin. ${ }^{3}$ Many papers in this literature claim that understanding self-selection is key to understanding the welfare impacts of migration, particularly in the receiving countries. Our paper is the first to test this assertion for a large number of countries. The counterfactual world in which every migrant is drawn randomly from his/her country of origin shuts off the forces of the Roy model of self-selection (Borjas, 1987), which are pervasive in virtually all migration flows around the world. Our simulations quantify the importance of self-selection for the welfare of non-migrants in the sending and receiving countries. We build on Biavaschi \& Elsner (2013), who analyze the impact of migrant selfselection based on detailed data from two episodes of mass migration to the US. In this paper, we simultaneously analyze the welfare effect for almost 150 countries. The welfare calculations reveal a substantial heterogeneity in the impact of migrant selection on the receiving countries. The impacts are large in countries with both a high share of immigrants and a high degree of skill bias, but small in most other countries.

Third, this paper relates to studies that estimate the global efficiency gains from migration. These studies typically evaluate the global impact of having more migration (Hamilton \& Whalley, 1984; Felbermayr \& Kohler, 2007; Klein \& Ventura, 2007, 2009; Iranzo \& Peri, 2009; Docquier et al., 2015a; Kennan, 2013; Battisti et al., 2014; Delogu et al., 2015; Docquier \& Machado, 2015; Clemens \& Pritchett, 2016) — in the extreme case, open borders — or the welfare contribution of migration at its current level compared to a world in autarky (Di Giovanni et al., 2015; Aubry et al., 2016). The welfare effect found in these papers is a combination of a scale effect - more vs. fewer migrants - and a composition effect, more high-skilled vs. more low-skilled migrants. Our counterfactual analysis isolates the composition effect by leaving the number of migrants constant while changing their skill composition, showing that the selectivity of migration alone is quantitatively important.

The remainder of the paper unfolds as follows. Section 2 establishes the stylized facts about skill-biased migration from the perspective of the sending and receiving countries. Section 3 presents the main features of the theoretical model and explains the channels through which skill-biased migration affects welfare. The calibration of the model is explained in Section 4. Section 5 presents the main simulation results of the welfare impact of skill-biased migration. In Section 6, we add a series of extensions and sensitivity checks. Finally, Section 7 concludes.

3 See Biavaschi \& Elsner (2013) for a review of the literature on the causes of migrant self-selection. 


\section{THE SKILL BIAS IN GLOBAL MIGRATION: STYLIZED FACTS}

Before quantifying its welfare impact, we present some stylized facts about the skill bias in global migration. We speak of a skill bias if the skill distribution of emigrants differs from that of the total population in the sending country. ${ }^{4}$ In most sending countries, the skill distribution of emigrants is heavily skewed towards high-skilled workers, i.e. the share of high-skilled workers among emigrants is often a multiple of the share of high-skilled workers in the total population.

In the sending countries, we measure the skill bias in emigration as the share of high-skilled workers among emigrants divided by the share of high-skilled workers in the total population,

$$
\text { skill bias }=\frac{\text { Share of high-skilled among emigrants }}{\text { Share of high-skilled in the total population }} .
$$

If this ratio equals 2 , then the share of high-skilled workers is twice as high among emigrants compared with the total population. Figure 1a) illustrates the extent of the skill bias for selected non-OECD countries in 2010. ${ }^{5}$ The vertical axis displays the skill bias, while the horizontal axis displays the share of emigrants in the total population. The dashed lines represent the median of each axis. At a value of 1 on the vertical axis, indicated by the thick line, the selection of emigrants from a particular country would be skill-neutral, whereby the share of high-skilled workers among emigrants equals the share of high-skilled persons in the total population.

For the vast majority of sending countries, the skill bias in emigration is positive. At the median of the countries displayed here, the skill bias is 2. For expositional reasons, we only display here countries with a maximum skill bias of 5 . However, some countries in the sample — for example, Mali — have a skill bias greater than $30 .^{6}$

In Figure 1b), we consider the perspective of the OECD countries. Here, the skill bias is calculated differently. The numerator is the share of high-skilled workers among immigrants in the current world with skill bias. The denominator is the share of high-skilled workers among immigrants under neutral selection, i.e. in the counterfactual world in which every migrant is randomly drawn from his/her respective country of origin. For instance, if the skill bias in a receiving country is 2 , then the share of high-skilled workers among immigrants is currently twice as large as it would be in a world in which all migrants are neutrally selected from their home countries. The higher the skill bias, the more positive the selection of migrants hosted in a particular OECD country. As shown in Figure 1b), most OECD countries attract a positive selection of immigrants. The skill bias is particularly large in countries with selective migration policies, such as Canada, the UK, the US, New Zealand and Australia. For instance, in Canada,

The total population comprises non-migrants as well as emigrants.

Both figures are based on the 2010 OECD-DIOC database. See Appendix E for the list of abbreviations.

These differences in the skill compositions of migrants can be explained by supply and demand factors. On the supply side, they reflect individual self-selection in the migration decision, i.e. the degree to which immigration is an attractive option for tertiary-educated workers and the varying level of attractiveness of different destinations for different groups. On the demand side, receiving countries apply different degrees of skill-based migration policies, which determine the characteristics of the immigrant population. The canonical model of migrant self-selection is provided by Borjas (1987). For a discussion of the empirical evidence, see Biavaschi \& Elsner (2013). 


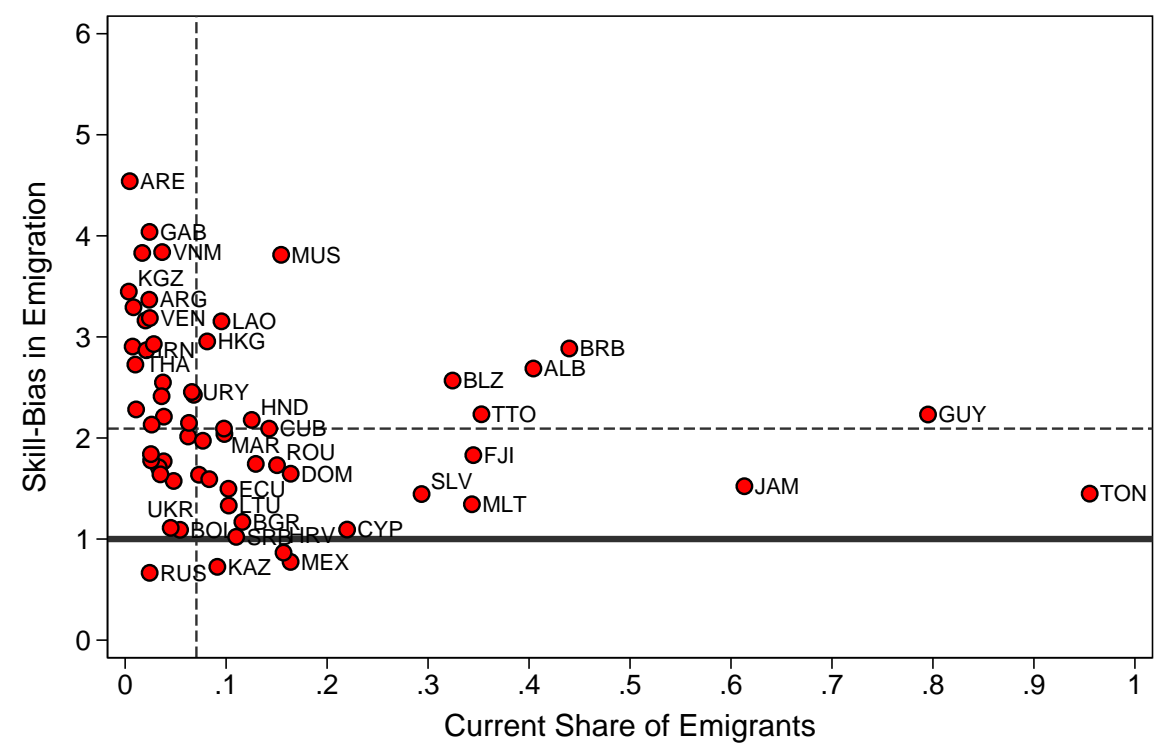

(a) Skill bias in emigration

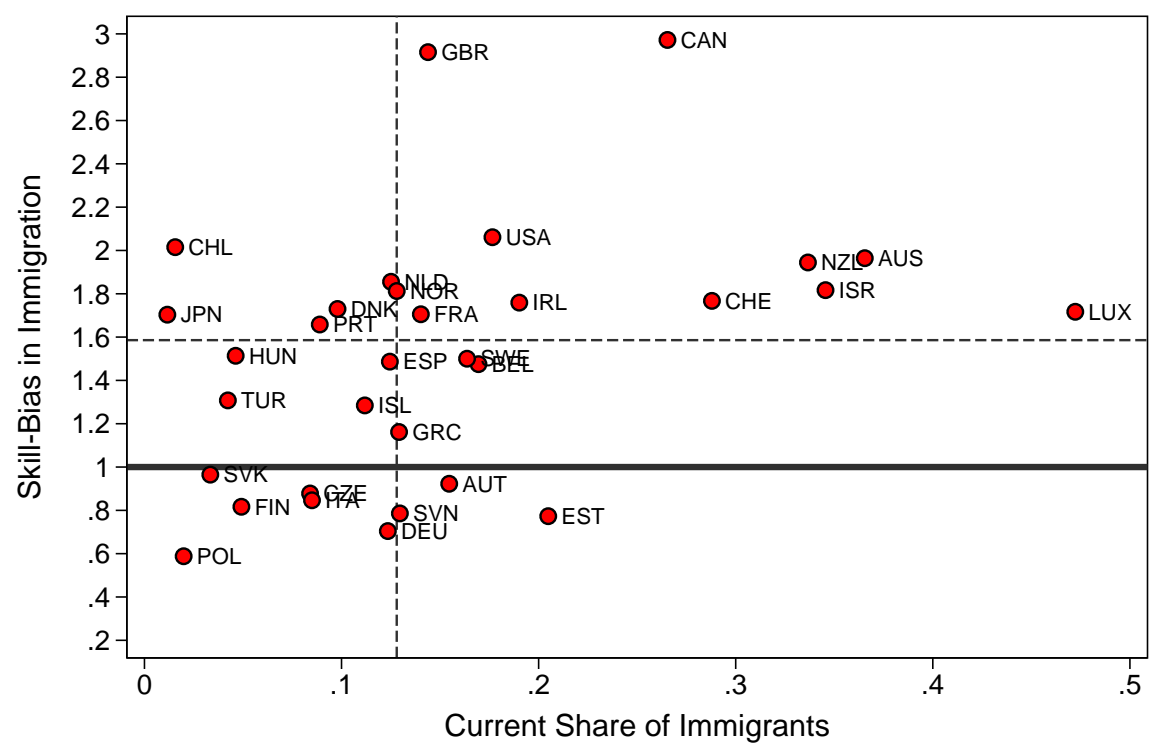

(b) Skill bias in immigration

Figure 1: The skill bias in immigration and emigration

Source: Own calculations from DIOC.

Notes: These graphs plot our measure of the skill bias in migration (vertical axis) on the share of emigrants and immigrants, respectively (horizontal axis), for the main sending countries (panel (a)) and the OECD countries (panel (b)). A value of 1 on the vertical axis indicates the absence of a skill bias. The dashed lines represent the median of both axes. In Panel (a), the denominator of the skill bias is the share of high-skilled workers in the total population of the sending country. In Panel (b), the denominator of the skill bias is the share of high-skilled among all immigrants that would be observed if migrants were randomly drawn from their countries of origin. 
the share of high-skilled immigrants is three times as large as it would be under skill-neutral migration. In some prominent immigration destinations - notably Germany, Italy and Austria - migrants are negatively selected, whereby their migrant stock would have higher skills under neutral selection.

In the analysis to follow, we will quantify the welfare impact of the skill bias in migration by comparing the current world with a strong skill bias in migration to a world with the same number of migrants, but a neutral selection of migrants. We expect the skill bias to have the largest impact in countries in the North-Eastern corner of Figures 1a) and b), namely those with both a high skill bias and a high share of migrants. The size of the effect will depend on many factors, such as the stage of a country's economic development, the skill structure of the labor market and trade flows.

\section{THEORETICAL FRAMEWORK}

To quantify the global welfare impact of skill-biased migration, we develop an integrated multicountry model that incorporates the most important adjustment channels through which a change in the skill composition of migrants affects welfare. We will calibrate the model to match key features of today's world, and use it to simulate a world in which the same number of migrants are neutrally selected from their origin country population. While the baseline model includes many important features of the global economy, it leaves out several important channels through which high-skilled emigration may benefit the sending countries, such as remittances, incentives to invest in education or trade creation through ethnic networks. We will introduce these in a series of extensions in Section 6.

\subsection{BASIC SETUP}

The basic setup of the model is in the spirit of Krugman (1980). We consider a world with $J$ countries, indexed by $i=1, \ldots, J$ and differentiated goods. In each country, the economy comprises two broad sectors: a traditional sector producing a homogeneous good $T$, and a horizontally differentiated manufacturing sector. The manufacturing sector comprises two sub-sectors, one producing a tradable differentiated good $X$, and one producing a non-tradable differentiated good $Y$. The market for manufactured goods $X$ and $Y$ is monopolistically competitive. Firms can freely enter the market, although they pay a sunk entry cost. Good $T$ is consumed domestically and not traded across countries, while the markets for the tradable differentiated good $X$ are separated by asymmetric iceberg trade costs. The real wage of workers in the traditional sector serves as numeraire.

Countries differ in terms of worker productivity. The workforce in each country comprises three education levels. ${ }^{7}$ Moreover, in the receiving countries, immigrants and natives are im-

$\overline{7} \quad$ We choose to have three education groups because this is the maximum number of available groups in our data. Ideally, we would like to have a more fine-grained skill distribution, similar to Biavaschi \& Elsner (2013), although such data is only available in a very small number of countries. 
perfect substitutes in production. In the baseline model, we assume that every migrant remits a fixed amount independent of income, in which case the country-pair-specific amount of remittances remains constant as long as the number of migrants does not change. ${ }^{8}$ In the remainder of this section, we present the main building blocks of the model. A more detailed description can be found in Appendix A.

\subsection{PREFERENCES AND WELFARE}

Consumers have non-homothetic preferences, whereby they always demand a certain amount of the traditional good $T$ independent of income. We think of the traditional good as a basket of goods necessary for survival, i.e. food and drinks. With non-homothetic preferences, an increase in average income translates into an over-proportional shift in consumption away from the traditional good and towards manufactured goods. This is particularly important for developing countries, where consumers spend a high fraction of their income on agricultural goods. A consumer in country $i$ with income $w_{i}$ maximizes utility

$$
\begin{aligned}
& \max _{\left\{T_{i}, x_{i j}(k), y_{i}(k)\right\}} \beta^{T}\left(T_{i}\right)^{\mu}+\left(1-\beta^{T}\right)\left[(1-\beta)\left(Y_{i}\right)^{\frac{\theta-1}{\theta}}+\beta\left(X_{i}\right)^{\frac{\theta-1}{\theta}}\right]^{\frac{\theta}{\theta-1}} \\
& \text { subject to: } P_{i}^{T} T_{i}+P_{i}^{Y} Y_{i}+P_{i}^{X} X_{i}=w_{i},
\end{aligned}
$$

where $\beta$ is the relative preference for the tradable differentiated goods, $\beta^{T}$ is a preference parameter for the traditional good, and $\theta$ is the elasticity of substitution between tradable and non-tradable goods $X$ and $Y$. The consumption of traditional goods is subject to decreasing marginal utility, such that $\mu<1 . Y_{i}$ and $X_{i}$ are CES composites of different varieties $k$ produced in the manufacturing sector,

$$
X_{i}=\left[\sum_{j=1}^{J} \int_{0}^{N_{j}^{X}}\left(x_{i j}(k)\right)^{\frac{\varepsilon-1}{\varepsilon}} d k\right]^{\frac{\varepsilon}{\varepsilon-1}}, \quad Y_{i}=\left[\int_{0}^{N_{i}^{Y}}\left(y_{i}(k)\right)^{\frac{\varepsilon-1}{\varepsilon}} d k\right]^{\frac{\varepsilon}{\varepsilon-1}} .
$$

$N_{i}^{X}$ and $N_{i}^{Y}$ are the numbers of varieties of goods $X_{i}$ and $Y_{i}$ available in country $i$. Varieties of the composite tradable good $X_{i}$ are either domestically produced, $x_{i i}(k)$, or imported from other countries $x_{i j}(k), j \neq i$, while all varieties of $Y_{i}$ are domestically produced. The parameter $\varepsilon$ is the elasticity of substitution between any two varieties within a sub-sector, with $\varepsilon>\theta>1$. Therefore, consumer preferences exhibit love of variety, which means that consumers gain utility when the number of available varieties increases.

We measure the welfare of a country's population or sub-population as the average indirect utility. Individual indirect utility is derived from the base consumption of good $T_{i}$, and the utility-maximizing consumption of varieties of the differentiated goods $X_{i}$ and $Y_{i}$. Thus, indirect utility equals the weighted average of the utility from consuming the traditional good, and the

\footnotetext{
$8 \quad$ We will later relax this assumption and provide extensions in which migrants remit a constant share of their income, as well as those in which high- or low-skilled migrants have a greater propensity to remit.
} 
utility from consuming manufactured goods divided by the price index in country $i$,

$$
U_{i}=\beta^{T}\left(\frac{\beta^{T} \mu}{1-\beta^{T}} \frac{P_{i}}{P_{i}^{T}}\right)^{\frac{\mu}{1-\mu}}+\left(1-\beta^{T}\right) \frac{w_{i}-T_{i}}{P_{i}} .
$$

where $P_{i}$ is the ideal price index in country $i$,

$$
\begin{gathered}
P_{i}=\left[(1-\beta)^{\theta}\left(P_{i}^{Y}\right)^{1-\theta}+\beta^{\theta}\left(P_{i}^{X}\right)^{1-\theta}\right]^{\frac{1}{1-\theta}}, \\
\text { with: } P_{i}^{X}=\left[\sum_{j=1}^{J} \int_{0}^{N_{j}^{X}}\left(p_{i j}(k)\right)^{1-\varepsilon} d k\right]^{\frac{1}{1-\varepsilon}} \text {, and } P_{i}^{Y}=\left[\int_{0}^{N_{i}^{Y}}\left(p_{i}(k)\right)^{1-\varepsilon} d k\right]^{\frac{1}{1-\varepsilon}} .
\end{gathered}
$$

A change in the selection of migrants affects welfare through incomes $w_{i}$ as well as the overall price level $P_{i}$. Both can be affected directly, for example through competition on the labor market, and indirectly through changes in market size, complementarities between workers of different skill levels or changes in trade patterns.

\subsection{LABOR FORCE COMPOSITION AND PRODUCTION}

Labor is the only production factor in the model. Countries have different levels of total factor productivity (TFP) in the traditional and manufacturing sector. Labor markets are assumed to be perfectly competitive. Workers sort into whichever sector pays the highest wage given their skill level. The traditional sector only produces with low-skilled workers,

$$
Q_{i}^{T}=A_{i}^{T} L_{i}^{T},
$$

where $L_{i}^{T}$ is the supply of low-skilled labor employed in the traditional sector, and $A_{i}^{T}$ is the productivity residual, which equals the real wage of low-skilled workers: $A_{i}^{T}=W_{i}^{L} / P_{i}^{T}{ }^{9}$

The manufacturing sector employs workers from all three skill levels and produces with a constant-elasticity-of-substitution (CES) technology. Workers with different skills are imperfect substitutes in production. The production function of the manufacturing sector is given by

$$
Q_{i}^{M}=A_{i}^{M} L_{i}^{M}=A_{i}^{M}\left[\alpha_{i}^{L}\left(L_{i}\right)^{\frac{\sigma_{s}-1}{\sigma_{s}}}+\left(1-\alpha_{i}^{L}-\alpha_{i}^{H}\right)\left(M_{i}\right)^{\frac{\sigma_{s}-1}{\sigma_{s}}}+\alpha_{i}^{H}\left(H_{i}\right)^{\frac{\sigma_{s}-1}{\sigma_{s}}}\right]^{\frac{\sigma_{s}}{\sigma_{s}-1}}
$$

In Equation (6), $L_{i}, M_{i}$ and $H_{i}$ represent the supplies of Low-, medium- and high-skilled workers. $L_{i}$ is the number of low-skilled workers not working in the traditional sector. $\alpha_{i}^{L}$ and $\alpha_{i}^{H}$ are the country-specific efficiency weights of low- and high-skilled workers.

In the receiving countries, each skill group comprises natives (labeled by superscripts $N$ ) and immigrants (with superscripts $F$ ), which are imperfect substitutes with a constant elasticity

$9 \quad$ This condition results from the profit maximization problem of firms operating on a perfectly competitive traditional sector. They set prices equal to the marginal cost of production, such that: $P_{i}^{T}=W_{i}^{L} / A_{i}^{T}$. Furthermore, wages of low-skilled workers are equal across sectors. Therefore, any low-skilled worker in sector $T$ has no incentive to move to sectors $X$ and $Y$. 
of substitution equal to $\sigma_{n}>1$. For example, the CES aggregate for high-skilled workers is given by

$$
H_{i}=\left[\left(1-\alpha_{i}^{F}\right)\left(H_{i}^{N}\right)^{\frac{\sigma_{n}-1}{\sigma_{n}}}+\alpha_{i}^{F}\left(H_{i}^{F}\right)^{\frac{\sigma_{n}-1}{\sigma_{n}}}\right]^{\frac{\sigma_{n}}{\sigma_{n}-1}},
$$

and likewise for medium- and low-skilled workers. The parameter $\alpha_{i}^{F}$ denotes the relative efficiency of foreigners versus natives of a given skill level. We allow $\alpha_{i}^{F}$ to vary across countries, but assume that it is the same across skill groups within a country.

The manufacturing sector is monopolistically competitive, such that firms have some pricesetting power. Each firm produces one variety of a differentiated good. Firms can freely enter the manufacturing sector, but incur a sunk entry cost of $f_{i}^{Y}$ and $f_{i}^{X}$ units of efficient labor in the respective sector. Sub-sectors $Y$ and $X$ both use identical production technologies. Firms within a country are homogeneous and set prices as a constant mark-up over the marginal costs of production,

$$
p_{i}(k)=p_{i}=\frac{\varepsilon}{\varepsilon-1} c_{i},
$$

where the $c_{i}=\frac{W_{i}}{A_{i}^{M}}$ is the marginal cost of production, and $W_{i}$ is the overall wage index of the manufacturing sector, given by

$$
W_{i}=\left[\left(\alpha_{i}^{L}\right)^{\sigma_{s}}\left(W_{i}^{L}\right)^{1-\sigma_{s}}+\left(1-\alpha_{i}^{L}-\alpha_{i}^{H}\right)^{\sigma_{s}}\left(W_{i}^{M}\right)^{1-\sigma_{s}}+\left(\alpha_{i}^{H}\right)^{\sigma_{s}}\left(W_{i}^{H}\right)^{1-\sigma_{s}}\right]^{\frac{1}{1-\sigma_{s}}} .
$$

Parameterization: Discussion Through the parameterization of the aggregate production function, we take into account four important differences in the economic structure between all 146 countries in our sample. First, countries differ in their productivity and consequently in their GDP per capita. The GDP per capita in Luxembourg - the OECD's richest country is five times larger than in Mexico, the OECD's poorest country. Moreover, in poorer countries the agricultural sector contributes a larger share to aggregate production. The productivity parameters $A_{i}^{T}$ and $A_{i}^{M}$ account for the differences in aggregate productivity across - as well as differences in - the sectoral productivity within countries. Second, as shown by Trefler (1993), countries considerably differ in their endowment of effective labor. For instance, the same highskilled worker is more productive in the US than in Mexico, because in the US he/she faces a higher complementarity between capital and skill. We account for these differences through country-specific efficiency parameters for high- and low-skilled workers, $\alpha_{i}^{L}, \alpha_{i}^{H}$. Third, within a country, workers with similar skills are closer substitutes in production than workers with different skills (Card \& Lemieux, 2001). We account for this imperfect substitutability by modeling the production function of the manufacturing sector with a CES structure. Fourth, as shown by Ottaviano \& Peri (2012) and Peri \& Sparber (2009), migrants and natives are imperfect substitutes even when they have the same level of education, which we account for in Equation (7) with an elasticity of substitution between immigrants and natives $\sigma_{n}<\infty$ and country-specific 
efficiency parameters $\alpha_{i}^{F}$.

\subsection{MARKET SIZE}

Each firm produces a single variety of a differentiated good. In equilibrium, firms make zero profits and all goods markets clear. These Conditions - together with the optimal pricing rule (8) - pin down the optimal number of varieties, $N_{i}^{X}$ and $N_{i}^{Y}$. To derive an expression for the optimal number of firms in sub-sectors $X$ and $Y$, we first derive the shares of value-added in the manufacturing sector, which are given by ${ }^{10}$

$$
s h_{i}^{X} \equiv \frac{P_{i}^{X} X_{i}}{G D P_{i}^{X}+G D P_{i}^{Y}}=\beta^{\theta}\left(\frac{P_{i}^{X}}{P_{i}}\right)^{1-\theta}, \text { and } s h_{i}^{Y}=(1-\beta)^{\theta}\left(\frac{P_{i}^{Y}}{P_{i}}\right)^{1-\theta},
$$

where $G D P_{i}^{X}$ and $G D P_{i}^{Y}$ are the sums of the wage bills of all workers in the respective sector. Combining Equation (10) and the optimal pricing rule (8) yields the resource constraints of the economy:

$$
s h_{i}^{X} A_{i}^{M} L_{i}^{M}=\frac{\varepsilon}{\varepsilon-1} N_{i}^{X} x_{i}, \quad s h_{i}^{Y} A_{i}^{M} L_{i}^{M}=\frac{\varepsilon}{\varepsilon-1} N_{i}^{Y} y_{i} .
$$

The resource constraints state that the effective labor supply in a given sector (left-hand side) has to equal labor demand by firms in this sector (right-hand side). The zero-profit condition implies that $p_{i} x_{i}=\varepsilon W_{i} f_{i}^{X}$ and $p_{i} y_{i}=\varepsilon W_{i} f_{i}^{Y}$, which yields the number of units produced by each firm,

$$
x_{i}=A_{i}^{M} f_{i}^{X}(\varepsilon-1), \quad y_{i}=A_{i}^{M} f_{i}^{Y}(\varepsilon-1) .
$$

Combining (11) and (12), we obtain the optimal market size

$$
N_{i}^{X}=\frac{s h_{i}^{X} L_{i}^{M}}{\varepsilon f_{i}^{X}}, \quad N_{i}^{Y}=\frac{s h_{i}^{Y} L_{i}^{M}}{\varepsilon f_{i}^{Y}},
$$

which states that the numbers of firms in sectors $X$ and $Y$, operating in country $i$, are proportional to the efficient labor supplies employed in these sectors and inversely proportional to the fixed costs of entry.

\subsection{INTERNATIONAL TRADE}

Varieties of the manufactured good $X$ are traded between countries. The volume of trade depends on trade costs, as well as differences in consumer demand and price levels. Exports from country $i$ to country $j$, denoted by Trade $_{j i}$, are subject to iceberg trade $\operatorname{costs} \tau_{j i}>1$. Trade costs are asymmetric, such that $\tau_{j i} \neq \tau_{i j}$. Trade ${ }_{j i}$ is given by

$$
\operatorname{Trade}_{j i}=\int_{k \in N_{i}^{X}} x_{j i} p_{j i} d k=N_{i}^{X} G D P_{j}^{X}\left[\frac{P_{j}^{X}}{\tau_{j i} p_{i}}\right]^{\varepsilon-1} .
$$

\footnotetext{
$\overline{10}$ Note that, by construction, $s h_{i}^{X}+s h_{i}^{Y}=1$, following from Equation (4).
} 
where $p_{j i}$ and $x_{j i}$ are the price and quantity of a variety produced in country $i$, consumed in country $j$. Given that $\varepsilon>1$, trade negatively depends on import prices and trade costs, $\tau_{j i} p_{i}$, and positively on the domestic price level. The total value-added in sector $X$ in country $i$ is computed as the sum of all trade flows to country $i$, including domestic consumption Trade $_{i i}$, and is given by

$$
G D P_{i}^{X}=N_{i}^{X} \sum_{j=1}^{J} G D P_{j}^{X}\left(\frac{P_{j}^{X}}{\tau_{j i} p_{i}}\right)^{\varepsilon-1} .
$$

Solving Equation (15) for $N_{i}^{X}$ and substituting into (14), we can express the share of exports as a total share of production in sector $X$ as

$$
\frac{\operatorname{Trade}_{j i}}{G D P_{i}^{X}}=\frac{G D P_{j}^{X}\left(P_{j}^{X} / \tau_{j i}\right)^{\varepsilon-1}}{\sum_{h=1}^{J} G D P_{h}^{X}\left(P_{h}^{X} / \tau_{h i}\right)^{\varepsilon-1}} .
$$

Equation (16) can be interpreted as a gravity equation. The share of exports from country $i$ to country $j$ in GDP of country $i$ increases with GDP in the foreign country. This ratio grows when the foreign price level increases and shrinks when bilateral trade costs increase. In Equilibrium, trade is balanced within each country, such that the value of imports equals the value of exports, $\sum_{j=1}^{J} \operatorname{Trade}_{i j}=\sum_{j=1}^{J} \operatorname{Trade}_{j i}$. In Appendix A.4, we provide a detailed definition of the equilibrium.

\subsection{MECHANISMS}

Within the model, a change in the skill distribution of migrants affects welfare through several channels. Here we highlight the most important mechanisms, using as an example a receiving country that switches to a more highly-skilled migrant population, such that the number of lowskilled migrants $L_{i}^{M}$ decreases while the number of high-skilled migrants $H_{i}^{M}$ increases by the same amount, $-\Delta L_{i}^{M}=\Delta H_{i}^{M}$, while assuming for simplicity that the number of medium-skilled migrants $M_{i}^{M}$ remains constant.

The change in the skill distribution of workers directly affects the nominal wage structure. Nominal wages of high-skilled workers decrease, while those of low-skilled workers increase. This affects the average nominal wage level, and especially affects the wages of non-migrants.

However, the change in the nominal wage structure affects wage inequality more than it affects welfare. A more important channel for welfare is market size, i.e. the number of available varieties. A workforce with a higher skill level is more productive, such that any good can be produced at a lower cost, whereby lower unit costs in turn induce more firms to enter the market, thereby increasing the number of varieties. As shown in Equation (4), a higher number of varieties reduces the price index, thus increasing welfare. This reflects consumers' love of variety, whereby their utility increases in the number of available varieties even if their income remains constant. The market size effect is propagated to other countries through trade linkages, which dampen the positive welfare effect at home, while increasing the welfare of all trading partners. 


\section{Data and Calibration}

We calibrate our model such that it replicates the most important features of the world economy in 2010: bilateral migrant stocks, bilateral trade flows, GDP per capita and wage differentials within countries. In terms of migration flows, we consider South-North migration from 111 countries to the OECD, as well as migration among the 34 OECD countries. Due to data limitations, we do not consider migration among non-OECD countries, assuming that SouthSouth migration remains constant in terms of scale and skill composition in both the baseline and counterfactual.

\subsection{DATA}

The calibration requires several types of country-specific and country-pair-specific macro variables for the reference year 2010. The sample consists of 34 OECD countries and 111 non-OECD countries. Non-OECD countries for which data is not available are lumped together in the Rest of the World (ROW). The list of countries and their abbreviations are available in Appendix E.

Migration AND population Data. Calibration requires data on the size and skill distribution of the migrant and non-migrant population of each country. The 2010 DIOC database provides data on bilateral stocks by education level of migrants who went from 111 sending countries to the OECD and migrants who moved between all 34 OECD countries, as well as the population size and skill distribution of natives in the 34 OECD countries. The definition of the three education levels is as follows: low-skilled individuals are those who achieved up to lower secondary or second stage of basic education; medium-skilled individuals obtained up to some post-secondary non-tertiary education; while high-skilled individuals have at least some tertiary education. To obtain the number and skill distribution of non-migrants for the nonOECD countries, we use data from Barro \& Lee (2010). ${ }^{11}$ For the Rest of the World, we apply the average skill distribution of the available non-OECD countries.

GDP, TRADE AND FIXED COSTS OF ENTRY. GDP per capita - in current international dollars - is taken from the World Development Indicators (WDI) database of the World Bank. The WDI database also provides the share of workers employed in agriculture and the shares in total GDP of traded and non-traded manufacturing goods. To compute the trade costs, we require a bilateral matrix of trade in value-added, which we construct by combining gross trade flows in 2010 from the UN Comtrade database and the share of value-added in trade from the OECD TiVA database. We impute missing trade flows based on an estimated gravity equation, details of which can be found in Appendix B.2. To obtain the fixed cost of entry in the tradable sector, $f_{i}^{X}$, we follow Di Giovanni et al. (2015) and use a component of the World Bank Easeof-Doing-Business indicator, which measures the number of days necessary to open a business. The longer that it takes to open a business, the more difficult it is to enter a market and the

$\overline{11}$ For more details on the aggregation of skill groups in both datasets, see Appendix B.1. 
higher the fixed costs of entering. We normalize the fixed costs for the US to 1 and compute the fixed costs relative to the US for all other countries.

WAGE RATios. To calibrate the efficiency parameters for high- and low-skilled workers $\left(\alpha_{H}\right.$ and $\alpha_{L}$ ), we require country-specific wage ratios for high- vs. medium-skill, $W_{i}^{H} / W_{i}^{M}$, and medium- to low-skill workers, $W_{i}^{M} / W_{i}^{L}$. For the OECD countries, we compute these ratios from the "Education at a Glance" report 2010 (OECD, 2010). For the non-OECD countries, we take data from the Wageindicator Foundation, which runs online-based surveys about wages in 80 countries. For the non-OECD countries, Wageindicator provides information on 38 highvs.-medium-skill, and 27 medium- vs.-low-skill wage ratios. ${ }^{12}$ For the remaining countries, we impute the wage ratios based on the returns to education in similar countries. A more detailed description of the imputation procedure can be found in Appendix B.3.

\subsection{CALibration OF KEY PARAMETERS}

We calibrate the model such that the generated data matches country-specific (i.e. GDP, population and wage structure) and bilateral (i.e. migration and trade) moments for the 146 countries in our sample (145 countries and ROW). To calibrate the most important structural parameters - preference parameters and elasticities of substitution between segments of the workforce we use estimates from empirical studies where available, and set the values of the remaining parameters similar to those found in other quantitative studies. To ensure that the choice of parameters does not fundamentally change the results, we will conduct a series of sensitivity checks. Table 1 summarizes the calibrated parameters.

The non-homothetic utility function ensures that the expenditure share of the traditional good decreases with income. This allows us to account for the higher fraction of income spent on traditional (i.e. agricultural) goods in developing countries, a standard observation in household datasets. ${ }^{13}$ Setting $\mu=0.5$ implies that the expenditure share on the traditional good decreases with income and increases with the price level $P_{i} \cdot{ }^{14}$

We set the relative preference for the tradable differentiated good, $\beta$, to 0.5 , such that individuals have the same preference for the traded and non-traded manufacturing goods. ${ }^{15}$ For the elasticity of substitution between tradable and non-tradable goods, $\theta$, we choose a value of $3 .{ }^{16}$ Following Simonovska \& Waugh (2014), the elasticity between any two varieties within a

12 See wageindicator.org for more information. A table with all wage ratios is available upon request.

13 As shown by the US Department of Agriculture, people in the US spent $6.8 \%$ of their total expenditure on food in 2011, whereas the expenditure shares in developing countries are considerably higher, for example $36.2 \%$ in Vietnam and $57.1 \%$ in Nigeria. http://www.ers.usda.gov/data-products/food-expenditures.aspx, viewed 19 Feb 2016.

14 Our model formulation imposes that $0<\mu<1$ to have a negative impact of the price level on the traditional good expenses. The results prove robust to the choice of this parameter value.

15 Note that real demand will also depend on prices, such that the quantities demanded for each good are not necessarily equal. A robustness analysis on this parameter shows that the results are not affected by this choice.

16 As we show in Appendix D, the simulation results are robust to a wide range of parameters, ranging from $\theta=0.5$ to $\theta=3.9$. 
Table 1: Values of structural parameters

\begin{tabular}{lll}
\hline Parameter & Value & Source \\
\hline $\begin{array}{l}\text { Preference } \\
\beta\end{array}$ & parameters & \\
$\beta^{T}$ & 0.5 & exogenous \\
$\theta$ & 0.139 & calibrated (match consumption to production) \\
$\mu$ & 3 & exogenous \\
$\varepsilon$ & 0.5 & exogenous \\
$\sigma_{s}$ & 4 & Simonovska \& Waugh $(2014)$ \\
$\sigma_{n}$ & 5 & Docquier et al. $(2014)$ \\
\multicolumn{4}{|l}{ Worker } & efficiency parameters \\
$a_{i}^{F}$ & 0.478 & calibrated to match OECD average \\
$a_{i}^{L}$ & $0.12-0.40$ & calibrated from FOC of cost minimization \\
$a_{i}^{H}$ & $0.24-0.60$ & calibrated from FOC of cost minimization \\
\hline
\end{tabular}

Note: This table summarizes the calibration of the structural parameters in the model. A more detailed description of the procedures can be found in the text of Section 4.2 and in Appendix B.

sector, $\varepsilon$, has the value of $4 .{ }^{17}$

The share of output produced by foreign workers $\left(a_{i}^{F}\right)$ is calibrated to match the educationspecific wage premia for natives over immigrants, which is $5 \%$ in OECD countries. For nonOECD countries, we use the average value obtained in OECD countries $\left(a_{i}^{F}=0.478\right)$ as we cannot assess country-specific values due to the lack of immigration data. The production function includes three types of workers. ${ }^{18}$ To calibrate its structural parameters, we use parameter values obtained by Ottaviano \& Peri (2012). To account for imperfect substitution between the three education groups, the elasticity of substitution, $\sigma_{s}$, is set to 5 . We further allow for imperfect substitution between immigrant and native workers within each skill group. The value of the elasticity of substitution, $\sigma_{n}$, is set to 20 , and is identical among the three skill groups. ${ }^{19}$

We subsequently calibrate the country-specific efficiency parameters for high- and low-skilled workers, $a_{i}^{H}$ and $a_{i}^{L}$, to perfectly match the high- vs. medium- and high- vs. low-skilled wage ratios within countries. We first use the market clearing condition for the manufacturing sector (Equation (26)) with data on GDP and the number of domestic and foreign workers per skill group to obtain the wage index for the manufacturing sector, $W_{i}$. The efficiency parameters are then obtained by inserting this information into the first-order conditions of a manufacturing

\footnotetext{
$\overline{17} \quad$ A value slightly higher is obtained by Parro (2013), who uses a tariff-based approach to estimate an aggregate trade elasticity for traded goods. Estimation of the shape parameter of the productivity distribution based on firm-level sales data provides values in the range of 3.6 to 4.8 (Bernard et al., 2003; Eaton et al., 2011). As we show in Appendix D, the simulation results are robust to changing the parameter values to $\varepsilon=3$ and $\varepsilon=5$.

18 In an extension, we will additionally account for skill discounting, i.e. the fact that some high-skilled immigrants work in low-skilled jobs.

19 All results are robust to changes in these parameters, as shown in Appendix D.
} 
firm's cost-minimization problem. With these parameters and the efficiency parameter of foreign workers, $\alpha_{i}^{F}$, we compute the skill-specific wage aggregates, $W_{i}^{L}, W_{i}^{M}$, and $W_{i}^{H}$. Based on the wage aggregates and $\alpha_{i}^{F}$, we compute the wages for all six types of workers.

Finally, we calibrate trade costs and TFP, such that the trade flows and cross-country TFP differences closely match their counterparts in the data. Based on these, we are able to compute all equilibrium prices and quantities, as well as the equilibrium number of firms. In Appendix B.4, we provide a more detailed description of the calibration procedure.

\section{THE GAIN FROM THE DRAIN - RESULTS}

We now use the calibrated model to run counterfactual simulations, in which we compare the world with and without skill bias in migration. Before doing so, we precisely explain how we construct the counterfactual and define the population whose welfare we are analyzing. For the simulations, we proceed in several steps. We first quantify the impact of the skill bias in migration on welfare in the sending and receiving countries, and further consider its impacts on wage inequality within countries. We then quantify the global welfare effect of skill-biased migration if all OECD countries were equally selective as Canada, the country with the highest degree of immigrant selectivity. We also simulate an alternative counterfactual, in which we reduce the number of high-skilled workers to the point where all migrant stocks are skill-neutral. Finally, we extend the model along several dimensions, including remittances, human capital externalities and network effects in trade.

\subsection{Counterfactual}

The aim of the simulation exercise is to quantify the welfare impact of the skill bias in migration, which requires constructing a counterfactual world without a skill bias in migration. To isolate the impact of the skill bias from the impact of changes in the scale of migration, we hold bilateral migration stocks fixed in both scenarios. In the baseline scenario - i.e. the current world - the skill composition of all migrant stocks has been shaped by the forces of the Roy model (Borjas, 1987). Within most sending countries, emigration is more beneficial for high-skilled compared to low-skilled workers, which is why we observe a positive skill bias in migration - and therefore a non-random selection of migrants - from most sending countries in the world. ${ }^{20}$

In our counterfactual, we eliminate the forces of the Roy model and assume that all migrants have been randomly drawn from their respective countries of origin. In this scenario, migration is not skill-biased, because emigrants have the same skill distribution as the total population of their home country. ${ }^{21}$

$20 \quad$ The Roy model presented in Borjas (1987) explains migrant selectivity through differences in income inequality between the sending and receiving countries, which make migration more profitable for some skill groups compared with others. The resulting selectivity could be positive or negative. Another theory — based on a human capital model - predicts a positive selection if all potential migrants face the same out-of-pocket moving costs but high-skilled workers have a greater earnings potential in the receiving country (Chiswick, 1999).

21 Critical readers might be concerned that our counterfactual is not the result of optimal migration decisions 


\subsection{Aggregate efFects}

\subsubsection{MEASURING WELFARE}

Before turning to the welfare effects, we need to define the population whose welfare we are analyzing. In our preferred analysis, our population of interest are never-migrants, i.e. people who are neither migrants under the baseline nor would they be migrants under the counterfactual.

An alternative would be welfare per capita, i.e. the average indirect utility of all individuals living in a particular sending or receiving country. However, while this measure is easy to understand and compute, it holds limited value because the skill composition of the underlying population differs between the baseline and the counterfactual. In the language of program evaluation, the difference in welfare per capita is a combination of a treatment effect - the causal impact of a change in migrant selectivity on the welfare non-migrants - and a composition effect, namely the result of replacing high-earning with low-earning migrants. We are interested in the treatment effect, i.e. the impact of the skill bias in migration on the welfare of people who are non-migrants under both the baseline and the counterfactual.

To isolate the pure treatment effect of the skill bias, we base our welfare calculation on the population of never-migrants. Constructing the skill distribution of this group is challenging because some people who are migrants in the current world would live in their country of origin under the counterfactual, and vice versa. This difference in the composition of the population would mechanically lead to a difference in welfare between the baseline and the counterfactual. We avoid this problem by considering only the welfare of groups that are non-migrants in both scenarios. We construct these as the minimum number of workers in a given skill group between the baseline and the counterfactual. For instance, the number of high-skilled never-migrants is $H_{N M}=\min \left(H_{\text {baseline }}, H_{\text {counterfactual }}\right)$.

Figure 2 provides further intuition for the construction of the population of never-migrants in the sending countries. It shows the skill composition of stayers in a migrant sending country in a scenario when over-proportionally many high-skilled workers have left the country (Panel A), and when the skill selection of migrants is neutral (Panel B), such that the number of highskilled workers at home is higher and the number of low-skilled workers is lower. Welfare per capita would be mechanically higher under the baseline than under the counterfactual. As we will show in the next section, isolating the treatment effect from this mechanical effect is very important, as the welfare effects are considerably higher per capita than per never-migrant.

The population of never-migrants is those residing in the country in both cases, as indicated by the dashed line. For simplicity, in this figure the numbers of high- and low-skilled nevermigrants are equal, although this need not be the case in the actual exercise. ${ }^{22}$

of all potential migrants in the sending countries. Nonetheless, the goal here is to provide a positive analysis and assess the quantitative importance of the skill bias in migration for the welfare of non-migrants. If one wanted extend the model to study alternative migration policies, a microfoundation of the migration decisions would be necessary. One could think of our counterfactual as the result of a policy that increases the migration costs of high-skilled workers while decreasing those of low-skilled workers until the skill distribution of migrants is the same as that of non-migrants. 
A. Skill-biased emigration

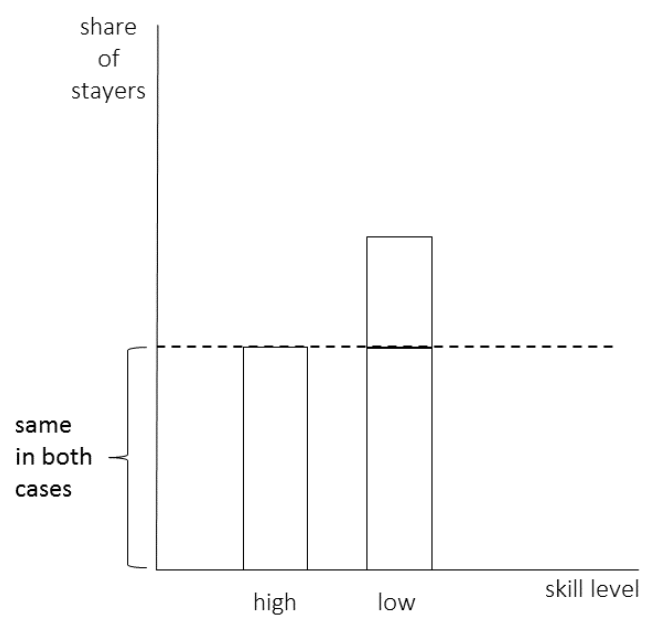

B. Skill-neutral emigration

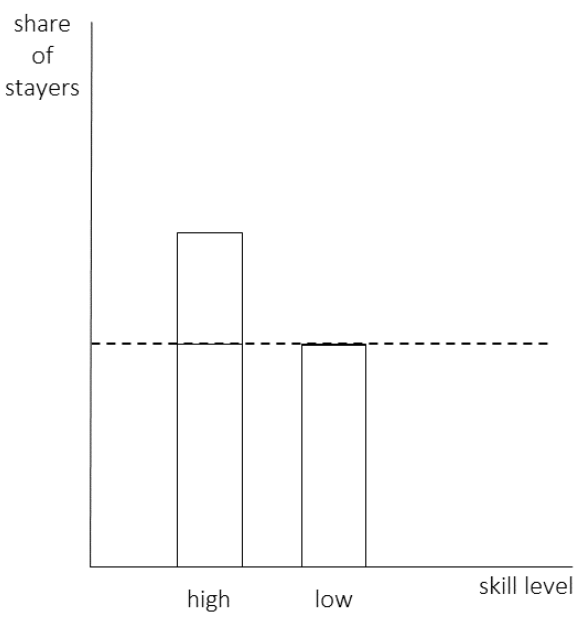

Figure 2: Skill distribution of stayers under the baseline and counterfactual.

Note: See text for explanation. This figure shows the skill composition of stayers in a migrant sending country in a scenario when over-proportionally many high-skilled workers have left the country (Panel A), and when the skill selection of migrants is neutral (Panel B), such that the number of high-skilled workers at home is higher and the number of low-skilled workers is lower. The population of never-migrants is those residing in the country in both cases, as indicated by the dashed line. For simplicity, in this figure the numbers of high- and low-skilled never-migrants are equal, although this need not be the case in the actual exercise.

\subsubsection{BASELINE RESULTS}

We begin by analyzing the impact of skill-biased migration on the average individual's welfare. We measure the change in welfare as the percentage difference in indirect utility,

$$
\frac{\Delta U}{U}=\frac{U_{\text {skill-bias }}-U_{\text {skill-neutral }}}{U_{\text {skill-neutral }}}
$$

Figure 3 displays the simulation results for selected receiving and sending countries, while Appendix E reports the full set of results. The countries are ordered from left to right by the share of immigrants or emigrants in the total population. All effects represent the difference in welfare under skill-biased versus skill-neutral migration. A positive effect means that people are better off under skill-biased migration. The dotted line represents the effect on welfare per capita, while the solid line represents the effect on welfare per never-migrant.

Figure 3(a) shows the effects for selected sending countries. These correspond to the welfare effects of the brain drain that have been estimated in the previous literature (Beine et al., 2008, e.g.). The effects are negative for all sending countries, and are particularly large for Jamaica and Haiti, both of which have large shares of emigrants, and whose emigrants are predominantly high-skilled. Depending on the welfare measure, the brain drain lowers the welfare in these two countries by $4-13 \%$, while in most other countries the welfare effects are smaller, at between 0

the utility function, because we only consider the welfare of people who would never migrate. 


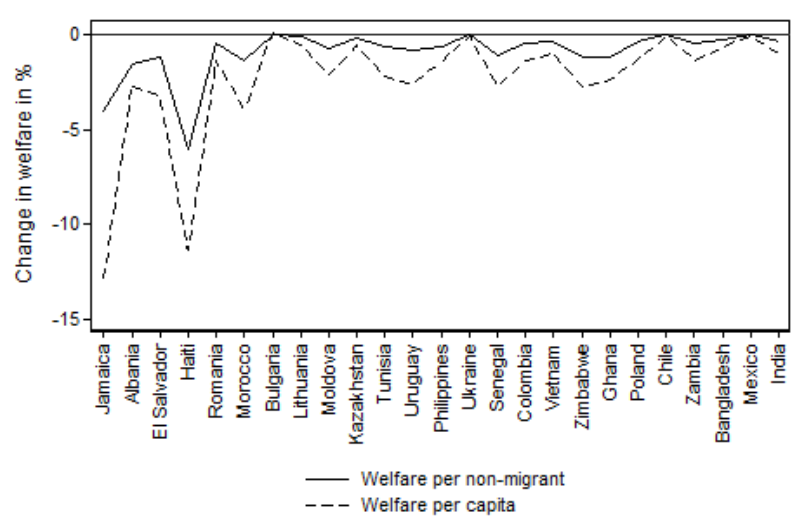

(a) Welfare Effects in the sending countries

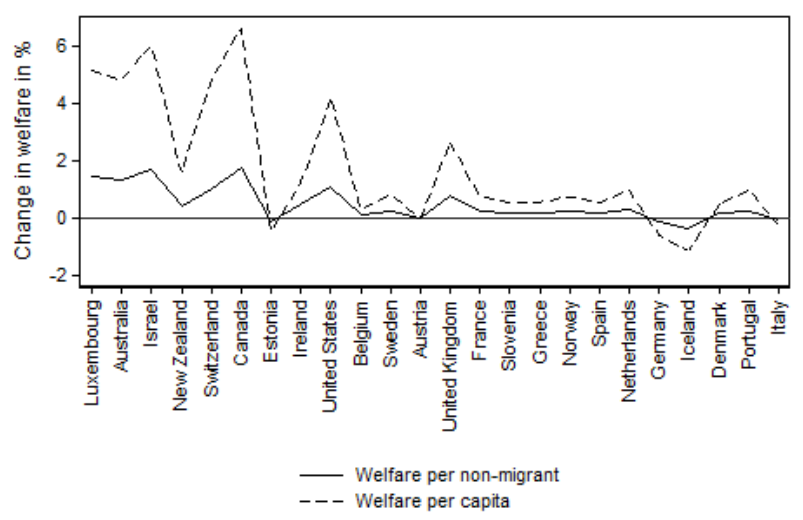

(b) Welfare Effects in the receiving countries

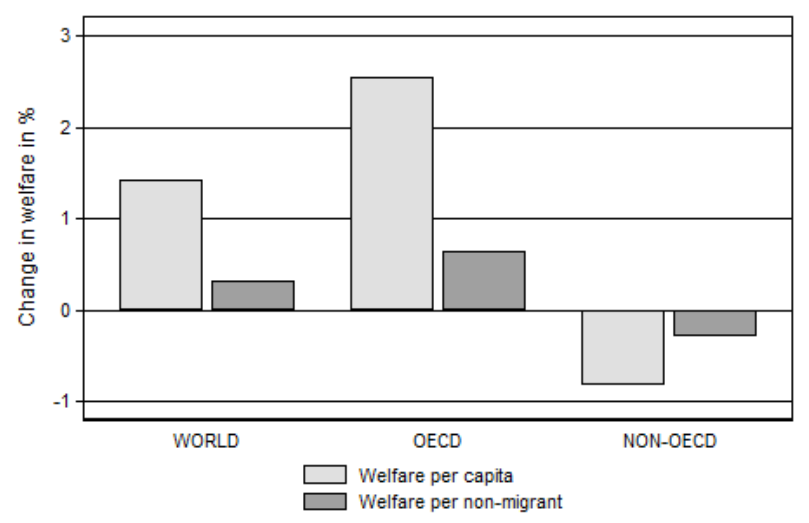

(c) Welfare Effects in OECD and non-OECD countries, and in the world

Figure 3: Baseline Welfare Effects

Source: Own calculations.

Notes: This graph displays the impact of the skill bias in migration on welfare in selected countries. The dashed line represents the effect on welfare per capita, while the solid line represents the effect on welfare per never-migrant. The countries on the horizontal axis are ordered by immigration and emigration rates, respectively, with the countries on the left having the highest migration rates. The vertical axis shows welfare changes, in percentage. Panel 3(a) focuses on selected sending countries, while panel 3(b) focuses on selected receiving countries. Panel 3(c) shows the average effect in all non-OECD and OECD countries as well as across the whole world.

and $3 \%$. The difference in the effect under both welfare measures highlights the importance of choosing the right base population. The effects are considerably larger when we consider welfare per capita, whereas the effect on welfare per never-migrant is smaller. In contrast to Beine et al. (2008), we do not find positive welfare effects for the brain drain, mainly because our baseline model does not include human capital externalities. As we will see in the extensions, once these externalities are included, some countries with low shares of emigrants - i.e. countries towards the right in Figure 3(a) - have small positive effects.

In Figure 3(b), we turn to the receiving countries. As shown in Section 2, the skill bias in 
migration is positive for most receiving countries, i.e. they receive more high-skilled immigrants than they would if all migrants were neutrally selected from their countries of origin. With the exceptions of a handful of countries, the impact of skill-biased migration is positive in all countries. The effects are particularly large in Canada, Australia, Israel, the US and Luxembourg, all of which combine high immigration rates with a high degree of selectivity. In the receiving countries, the difference in the effect on both welfare measures is more pronounced than in the sending countries. The impact on welfare per never-migrant is considerably smaller than the impact on welfare per capita. Nonetheless, the effect on welfare per never-migrant is positive for most countries, at between 0 and $2 \%$. Across the OECD as a whole, welfare is about $0.7 \%$ higher due to the skill bias in migration.

Upon first glance, it seems that the effects in the sending countries are larger than in the receiving countries. However, once we weight the effects by population and compute the net effect on the world - shown in Figure 3(c) — we find that the gains in the receiving countries exceed the losses in the sending countries, leading to a $0.3 \%$ gain in world welfare. What seems like a small effect is actually large given the small share of migrants among the world population. At present, only $3 \%$ of the world population is migrants, whereby world welfare is $0.3 \%$ higher simply because these $3 \%$ are predominantly high- and not low-skilled. Moreover, this result represents a conservative estimate of the global welfare effect, because the simulations do not include any externalities through which the sending countries could benefit from skill-biased migration.

\subsection{Distributional EFFECTS}

Besides having an impact on aggregate welfare, the skill bias in migration also affects the income distribution within a country. A change in the skill composition of migrants alters the relative supply of high- vs. low-skilled workers, which in turn affects the nominal wage structure. Nominal wages are affected through direct competition on the labor market, as well as through complementarities between high-, medium- and low-skilled workers.

Figure 4 displays the impact of the skill bias in migration on the real wages for different education levels. As in the previous section, a positive value means that the respective groups have higher real wages in a world with skill-biased migration. Figure 4(a) shows the distributional effects in the sending countries. In all sending countries, high-skilled workers gain and low-skilled workers lose, while the impact for medium-skilled workers hovers around zero. The gains in real wages are particularly pronounced for high-skilled workers in Albania $(+24 \%)$, Haiti $(+25 \%)$ and Zimbabwe $(+19 \%)$, while in most other countries the effects are close to zero. In most countries, the gains for high-skilled workers are larger than the losses for the low-skilled workers. The sign of the effects can be explained by a simple supply-and-demand mechanism. Most sending countries experience a severe brain drain, such that high-skilled workers who stay behind become a scarcer resource in the labor market, leading to wage increases. The opposite holds true for low-skilled workers. The magnitude of these effects depends on the skill distribution of the nonmigrant population, as well as the direction and magnitude of the general equilibrium effects. 
Overall, the skill bias in migration increases the wage wage gap between high- and low-skilled workers in sending countries.

As Figure 4(b) shows, the skill bias has the opposite effect in the receiving countries: lowskilled workers gain, while high-skilled workers lose. The gains for low-skilled workers have two sources: first, with skill-biased migration, they face less competition on the labor market, leading to higher nominal wages; and second, they benefit from the market size effect due to a larger number of available varieties and lower prices. For high-skilled workers, the effects are less clear. In most countries, high-skilled workers lose by a small margin, while they gain in others. High-skilled workers benefit from the same positive market size effect as low-skilled workers, although they face more competition on the labor market. If these effects balance out, the net effect may be zero. Overall, the skill bias in migration reduces the wage gap between high- and low-skilled workers in the receiving countries.

The gains for low-skilled workers in the receiving countries may seem puzzling in light of the evidence that migration reduces the wages of low-skilled natives (Borjas, 2003; Dustmann et al., 2013). The main difference between these studies and ours is the choice of counterfactual. Most studies explore the impact of having more immigrants, whereas our interest lies in the impact of having different immigrants. Given that under skill-biased migration the receiving countries have fewer low-skilled immigrants than under the counterfactual, low-skilled non-migrants are better off under skill-biased migration.

We also report the real wage changes for the OECD and the world as a whole, as shown in panel (c). Low-skilled non-migrant workers in the OECD gain about $3 \%$, and low-skilled workers in the world gain around $2 \%$, while the effects for high-skilled workers are close to zero. Taken together, the results from Section 5.2.2 and this section suggest that skill-biased migration leads to a more efficient allocation of labor and greater productivity in the world, although it also increases income inequality within countries.

\subsection{Simulating the Canadian model for the OECD}

The simulation results shown thus far provide an estimate for the welfare effect of the current skill bias in migration. We now turn to a hypothetical scenario that could occur if the OECD countries introduced a more selective immigration policy towards non-OECD countries. As an example we use Canada, which has the largest degree of skill bias among all OECD countries. Based on this example, we carry out the following thought experiment: assuming that immigrants in every OECD country were as strongly selected as in Canada, what would be the impact of this skill bias on global welfare? ${ }^{23}$

Figure 5 provides the answer, showing the effects on welfare per never-migrant. The welfare consequences for most sending countries - especially for those with high shares of emigrants - would be drastic. For example, Albania — whose emigrants are currently almost neutrally

\footnotetext{
23 More specifically, we apply the skill selection of Canada vis-a-vis every sending country to every other OECD country. For example, if $80 \%$ of all Turkish migrants in Canada have a college degree, then we assume that $80 \%$ of all Turkish migrants to Germany also have a college degree.
} 


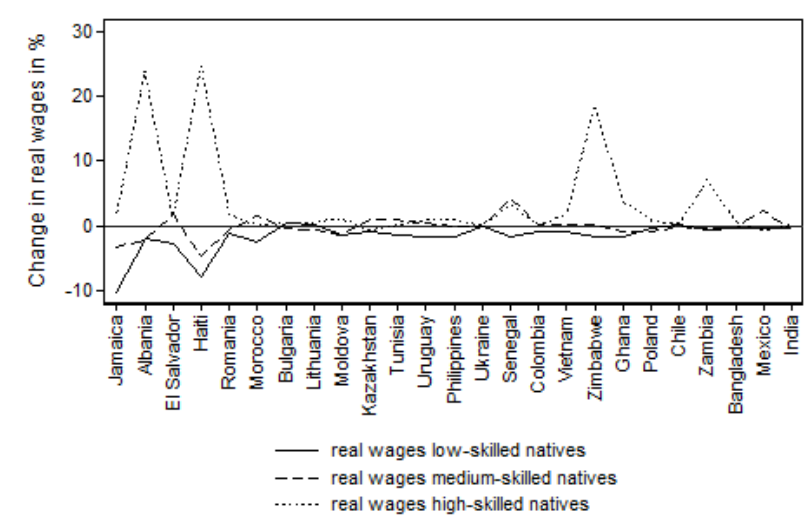

(a) Wage Effects in selected non-OECD sending countries

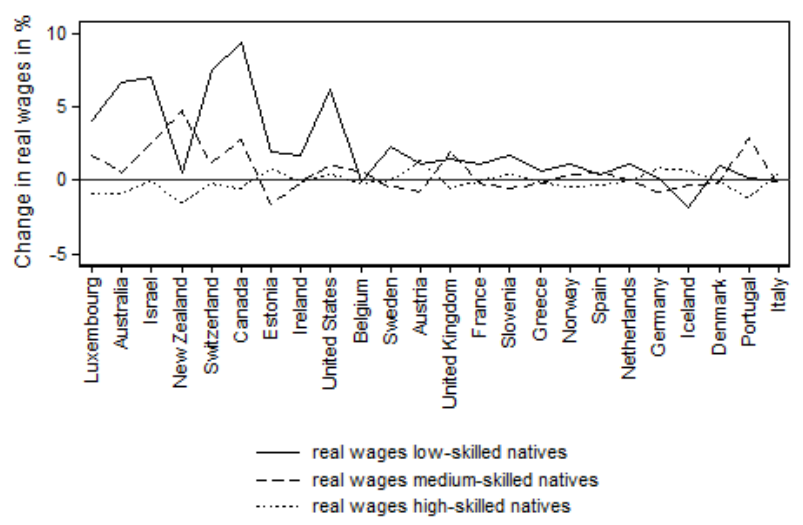

(b) Wage Effects in selected OECD receiving countries

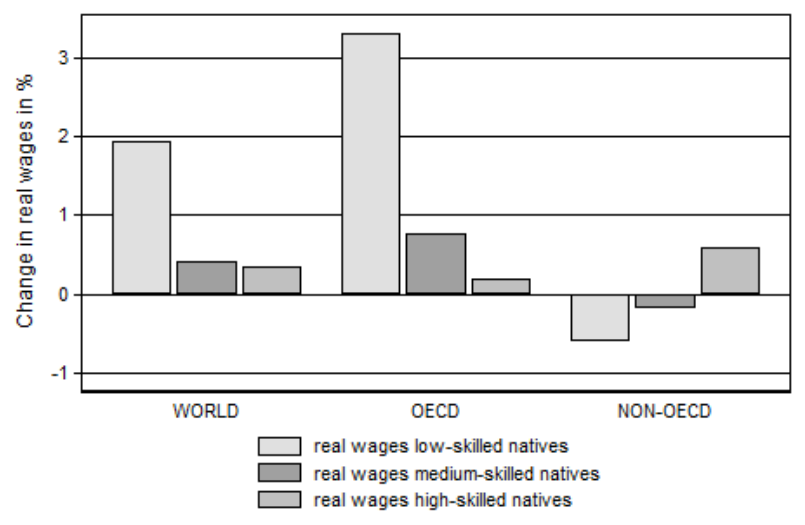

(c) Wage Effects in OECD and non-OECD countries, and in the world

Figure 4: Distributional effects

Source: Own calculations.

Notes: This graph shows the impact of the skill bias in migration on the real wages of low-, medium- and high-skilled workers. The countries on the horizontal axis are ordered by emigration and immigration rates, respectively. The vertical axis shows wage changes, in percent, for high- and low-skilled workers.

selected - would see a much larger share of high-skilled emigrants, experiencing a welfare loss four times larger than under the current skill bias in migration. In the OECD countries, the welfare effects are larger than under the current selection of migrants. ${ }^{24}$

Importantly, the impact on world welfare is larger than under the current selection of migrants. This suggests that it would be globally efficient to have an even greater skill bias in migration, because larger numbers of productive workers would be in countries where their skills are most efficiently used. Nonetheless, the consequences for some sending countries could be

24 In some OECD countries, the effects under the 'Canadian regime' are smaller than under the baseline scenario, despite Canada being the most selective country. This selectivity is high on average, although it may be lower vis-a-vis some sending countries. For example, if the Polish immigrants in Canada are less positively selected than Polish immigrants in Ireland, the welfare effect in Ireland can be larger in the baseline simulations. 


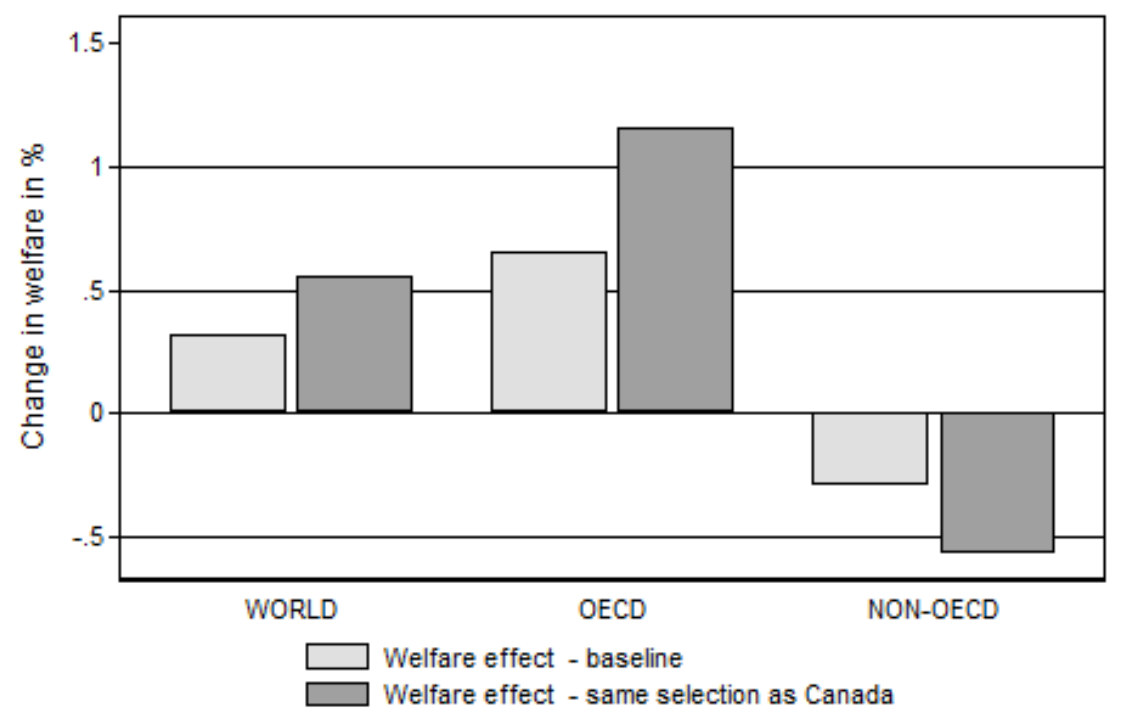

Figure 5: OECD as selective as Canada

Source: Own calculations.

Notes: This graph displays the welfare effects of the skill bias in migration if all OECD countries were as selective as Canada. The vertical axis shows changes in welfare per never-migrant in percent.

severe. However, in light of the global efficiency gains, it should be possible to combine a selective immigration policy with a compensation scheme, according to which the receiving countries compensate the sending countries for the welfare losses from skill-biased migration.

\subsection{Changing THE NUMBER OF HIGH-SKILlED MIGRANTS ONLY}

The central aim of our analysis is to assess the contribution of the skill bias in migration to global welfare. For this purpose, it is useful to keep the number of migrants constant, which allows us to isolate the welfare impact of a change in the skill composition from a change in the scale of migration. But this is not the only counterfactual that would remove the skill bias in migration. Another possibility, introduced by Beine et al. (2008), is to reduce the number of high-skilled emigrants until the emigration rates of high-skilled workers equal those of low- and medium-skilled workers.

We construct this counterfactual separately for each origin-destination country pair. If an origin country has a skill-bias in emigration vis-a-vis a given destination country, we repatriate high-skilled migrants up to the point where the skill bias within each country pair is eliminated. Take as a hypothetical example that $1 \%$ of all Senegalese low- and medium-skilled workers have emigrated to France, whereas among high-skilled Senegalese the emigration rate to France is $2 \%$. In this case we would repatriate half of all high-skilled Senegalese immigrants from France, such that the high-skilled emigration rate gets reduced to $1 \%$.

This new counterfactual is interesting for two reasons. First, it is more likely to be consistent with actual migration policy in most destination countries. The current positive selectivity 
in migration is partly the result of destination countries imposing lower migration barriers for high-skilled than for low-skilled workers. On the other hand, one could see the counterfactual as a policy proposed by Collier (2013), who suggests that rich countries should restrict high-skilled migration to foster development in poor countries. Therefore, this exercise can inform us about the welfare implications of such a policy. Second, this exercise reveals the welfare contribution of relocating the best and brightest individuals from low-productivity to high-productivity countries, as it measures the marginal effect on non-migrants of having one more high-skilled immigrant in destination countries and one fewer high-skilled emigrant in the countries of origin.

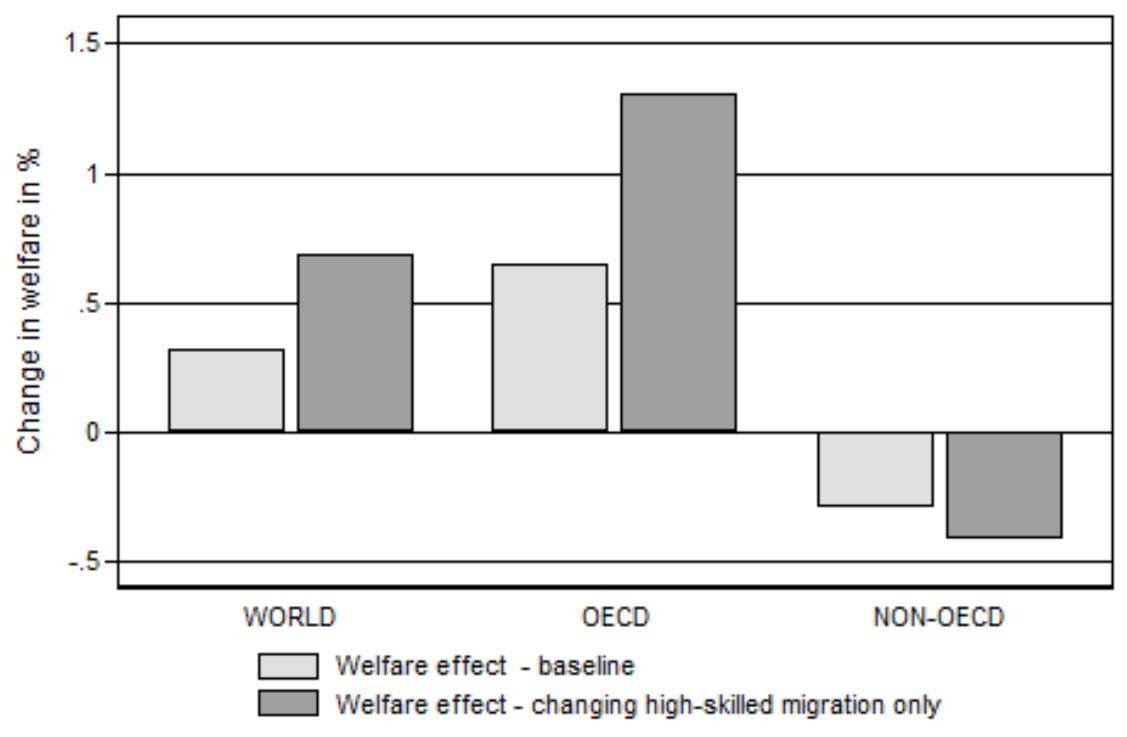

Figure 6: Welfare effects of increasing high-skilled migration only

Source: Own calculations.

Notes: In this graph we compare the welfare effect of skill-biased migration obtained by changing the number of high skill migrants only. The vertical axis shows changes in welfare per never-migrant in percent.

Figure 6 depicts the results from this analysis. In both the OECD and non-OECD countries, the welfare difference between the current world and the counterfactual are larger compared to our baseline simulations with a constant stock of migrants. The welfare difference between both scenarios is mainly explained by the difference in market size, which is influenced by two forces. First, it decreases with a higher share of low- and medium-skilled workers. Intuitively, if the share of low-skilled workers is higher, then each firm is on average less productive, and firms exit the market. Second, market size decreases as the number of workers becomes smaller, because demand is lower while the fixed costs of entry remain constant. In this alternative counterfactual, we reduce the number of high-skilled workers in the destination countries while leaving the number of low-skilled workers constant. This reduces the overall number of workers, increases the share of low-skilled workers in the destination countries' workforce and, thus, reduces market size. The opposite mechanism applies to the the origin countries. Consequently, the larger welfare differences indicated by the dark bars in Figure 6 are driven by a larger 
difference in market size.

These results suggest that moving from the current world to a world with skill bias in migration and 27 million high-skilled migrants to a world without skill bias and 9 million highskilled migrants would reduce the global welfare for never-migrants by $0.7 \%$. An alternative interpretation is that the average never-migrant in the current world is $0.7 \%$ better off compared to a world in which migration restrictions for high-skilled workers would set the skill bias in migration to zero.

\section{EXTENSIONS}

Our model incorporates some of the most important adjustment channels through which a change in the migrant skill distribution affects welfare, namely market size, trade flows and changes in the nominal wage structure. In this section, we incorporate several additional mechanisms that have been highlighted in the literature: remittances, incentives to invest in education, TFP externalities and trade creation through ethnic networks. We also account for downskilling, i.e. the fact that many immigrants work in occupations for which they are over-qualified. Furthermore, we put the welfare impact of the skill bias into perspective by comparing it with the welfare difference between today's world and a world with zero migration.

\subsection{Remittances}

Remittances are an important source of income in developing countries, and could potentially offset the negative market size effect of skill-biased migration in the sending countries. In the baseline model, we do not explicitly include remittances, although we implicitly assume that every migrant remits the same amount independent of earnings. This assumption is supported by parts of the empirical literature, finding a weak correlation between earnings and the amount remitted per migrant (Bollard et al., 2011; Faini, 2007; Niimi et al., 2008).

However, it is possible that higher-earning migrants send a higher amount of remittances, or that the propensity to send remittances depends on the skill level. In several extensions, we account for these different possibilities. First, we assume that every migrant remits a constant fraction of her income abroad. Consequently, under skill-biased migration the amount remitted per migrant should be larger than in a world without skill bias, because high-skilled migrants earn more than low-skilled migrants. Therefore, we would expect remittances to dampen the negative effect of skill-biased migration in the sending countries.

To account for differences in the share of income remitted across sending and receiving countries, we compute country-pair-specific shares based on remittance data from the World Bank. ${ }^{25}$ In the origin countries, we assume that remittances are given and are equally distributed

\footnotetext{
$\overline{25}$ We obtain country-pair-specific remittances based on the methodology developed by Ratha and Shaw, 2007, "South-South Migration and Remittances," Development Prospects Group, World Bank (www .worldbank. org/prospects/migrationandremittances). The remittance data cover 2010, and are disaggregated using host country and origin country incomes from 2010, as well as estimated migrant stocks from 2010. The share of remittances in income is calculated as the total amount of remittances sent from a given destination
} 
across the population as a lump-sum transfer.

The welfare effects with a constant amount of remittances per person and a constant share of income remitted are presented in Figure 7. The lighter grey represents the baseline effect, i.e. the difference in welfare per never-migrant when every migrant remits a constant amount. The darker grey shows the welfare effect when migrants remit a fixed share of their income. In the non-OECD countries, remittances that depend on income dampen the negative welfare effect. This result is consistent with other studies showing that remittances play an important role in explaining the overall impact of migration on welfare; for example, Di Giovanni et al. (2015). In the OECD countries, remittances do not particularly contribute to the overall welfare effect. ${ }^{26}$

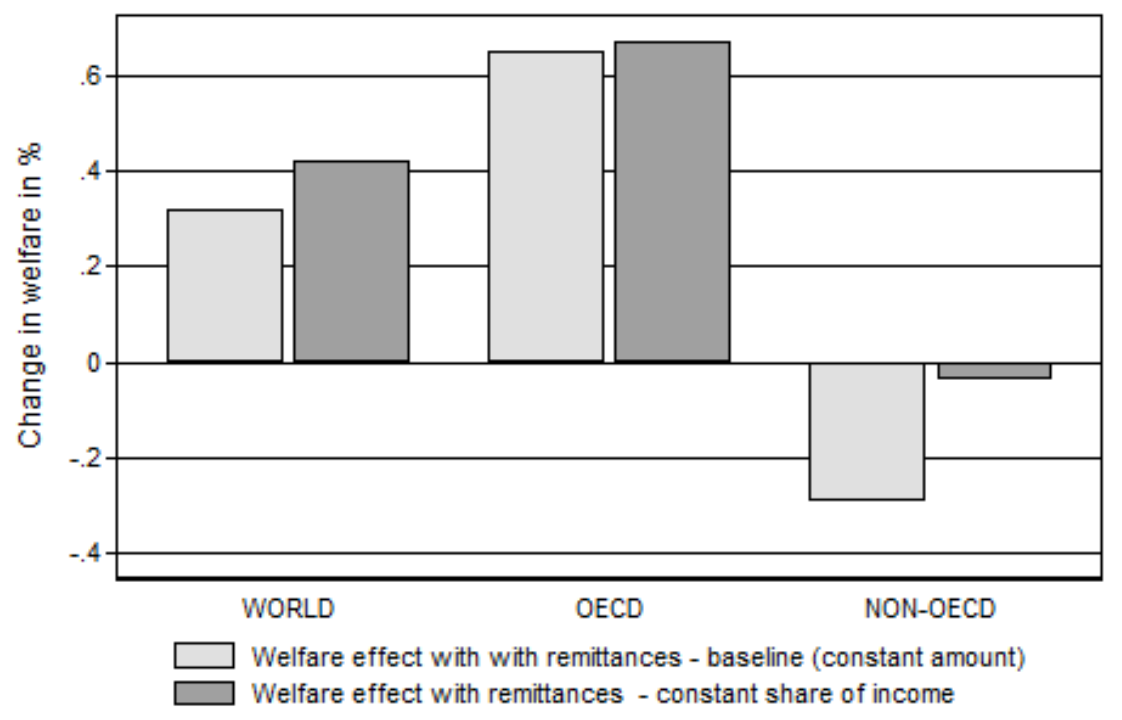

Figure 7: Welfare effects with remittances

Source: Own calculations.

Notes: This graph displays the welfare effects of the skill bias in migration with a constant amount remitted and a constant share of income remitted. The vertical axis shows changes in welfare per never-migrant in percent.

In a second extension, we allow for different propensities to remit across education groups. ${ }^{27}$ The results for various propensities to remit are displayed in Appendix C.1. Across all scenarios, the introduction of remittances dampens the welfare impact of skill-biased migration on the sending countries, while having almost no impact on the receiving countries.

country divided by the total immigrant wage bill in that country.

26 The small increase in welfare in OECD countries primarily derives from the increase in remittances to OECD countries from OECD emigrants.

27 There is some empirical evidence on skill-specific remittance rates. For instance, Faini (2007) and Niimi et al. (2008) show that more educated remit a smaller fraction of their income, because they tend to come from richer families that are less in need of remittances. By contrast, based on microdata Bollard et al. (2011) show that more educated migrants - conditional on remitting at all — remit more. 


\subsection{BRAIN GAIN - INVESTMENT IN EDUCATION}

While the traditional literature on the brain drain predicted severe negative welfare effects for the sending countries, more recent literature has highlighted that human capital externalities may partially offset the losses in the sending countries, even leading to a 'brain gain' in a more optimistic scenario. As shown in theoretical works by Mountford (1997), Stark et al. (1997) and Beine et al. (2001), the opportunity to emigrate increases the returns to education, leading to higher investment in education. This can have a positive welfare effect if not everyone who invested in education leaves the country. Several micro-studies provide evidence of a substantial response of investment in education to improvements in the possibility to migrate (Chand \& Clemens, 2008; Batista et al., 2011; Shrestha, 2015; Dinkelman \& Mariotti, 2016). Moreover, at the macro level, Beine et al. (2008) find that the brain gain offsets the negative brain drain effect in sending countries with low emigration rates, while in countries with high emigration rates the negative effect dominates.

To incorporate a brain gain mechanism into the model, we endogenize the share of highskilled stayers in the sending countries. ${ }^{28}$ Define $s h_{S}=\frac{H_{n}}{H_{n}+M_{n}+L_{n}}$ and $s h_{E}=\frac{H_{e}}{H_{e}+M_{e}+L_{e}}$, respectively, as the observed share of high-skilled stayers and emigrants under the baseline scenario, and $\widehat{s h_{S}}$ and $\widehat{s h_{E}}$ as the equivalent shares under the counterfactual. We compute the new counterfactual share of high-skilled stayers as

$$
\widehat{s h_{S}}=s h_{S}\left(1+\sigma_{b} \frac{\widehat{s h_{E}}-s h_{E}}{s h_{E}}\right)
$$

The elasticity $\sigma_{b}$ describes the strength of the brain gain mechanism. If $\sigma_{b}=0$, there is no additional investment in education, whereas if $\sigma_{b}$ is positive, the share of high-skilled stayers becomes an increasing function in the share of high-skilled emigrants. We calibrate the model using elasticities between 0 (no brain gain effect), and 0.05 , the brain gain effect estimated in Beine et al. (2008). To compute the counterfactual skill distribution in the sending countries, we implement an iterative procedure that simultaneously solves for $\widehat{s h_{S}}$ and $\widehat{s h_{E}}$, and computes the shares of low- and medium-skilled stayers as residuals. Appendix C.2 explains the detailed procedure.

The simulation results are displayed in Figure 8. The brain gain channel dampens the welfare losses from skill-biased migration in the sending countries, even leading to an overall welfare gain in some cases. The receiving countries are only mildly affected due to general equilibrium effects. With a brain gain elasticity of $\sigma_{b}=0.05$, the impact of the skill bias in migration on world welfare is twice as large as without a brain gain mechanism. However, one should be cautious when interpreting the difference in results with and without brain gain because they do not represent marginal effects. In some countries, the share of high-skilled emigrants under the baseline is a multiple of the share of high-skilled emigrants under the counterfactual. Thus, an elasticity of $\sigma_{b}=0.05$ is probably too high to account for these substantial differences in high-skilled

\footnotetext{
28 This represents a reduced-form relationship. The underlying microfoundations have been described in Mountford (1997) and Stark et al. (1997).
} 


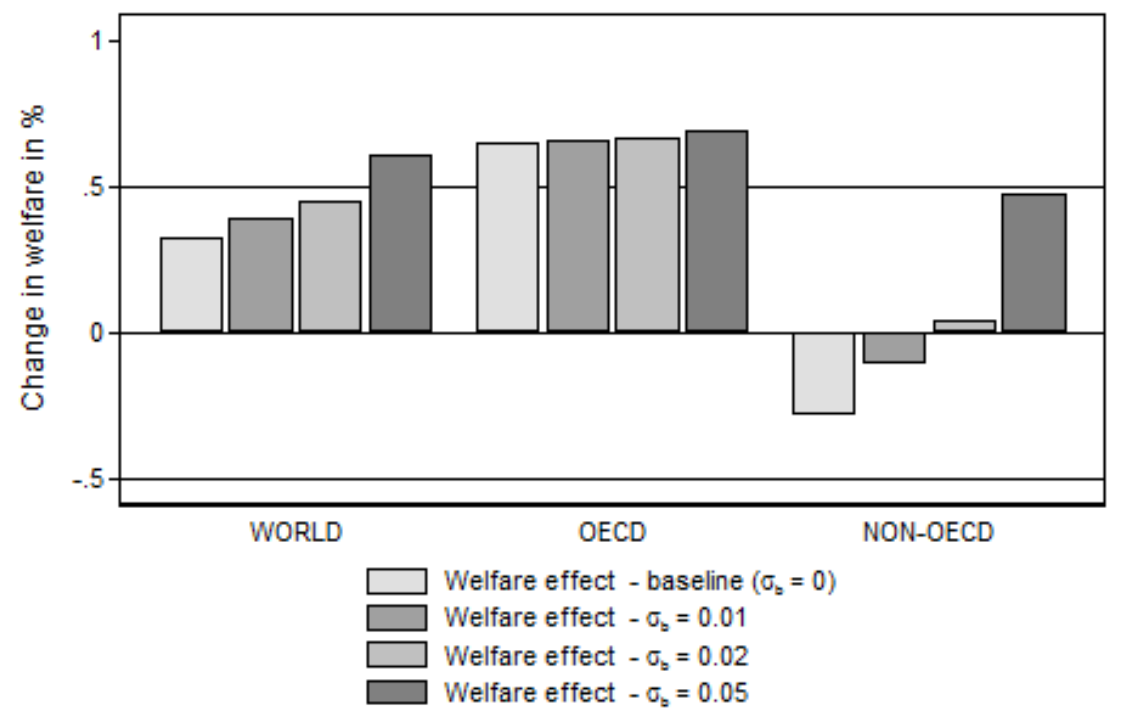

Figure 8: Allowing for brain gain

Source: Own calculations.

Notes: This graph displays the welfare effects of the skill bias in migration allowing for incentives to invest in education in the sending countries. The vertical axis shows changes in welfare per never-migrant in percent.

emigration rates. However, even at a modest brain gain elasticity of $\sigma_{b}=0.01$, the welfare losses in the sending countries are considerably lower than in a world without brain gain.

\subsection{HUMAN CAPITAL EXTERNALITIES IN TFP}

A further human capital externality could work through total factor productivity (TFP). As shown by Lucas (1988), an economy with a higher average level of human capital may use its production factors more efficiently, leading to an additional positive impact of human capital on output. We incorporate a Lucas-type externality in the model, with TFP being a concave function of the average level of human capital. Consequently, a marginal change in the level of human capital has a larger effect in poorer countries, which start from a lower level of human capital. ${ }^{29}$ We parameterize total factor productivity as

$$
A_{i}=a_{i}\left(\frac{H_{i}}{H_{i}+M_{i}+L_{i}}\right)^{\sigma_{a}}
$$

The elasticity $\sigma_{a}$ governs the strength of the response of TFP to changes in the share of highskilled workers in the population. We run separate simulations for $\sigma_{s} \in\{0.1,0.3,0.5\} .^{30}$ The

$29 \quad$ An alternative interpretation of this externality could be that high-skilled emigration in one generation reduces the productivity of the next generation if it reduces the opportunity of the next generation to get educated, or if it leads to less innovation. While our model does not include multiple generations, one could interpret this externality as a reduced-form representation of a multigenerational feedback mechanism between human capital and productivity.

30 The parameters estimated in the empirical literature widely vary. While Acemoglu \& Angrist (2000) find an elasticity close to zero, Iranzo \& Peri (2009) find a value close to 0.44. Moretti (2004b,a) finds values 
parameter $a_{i}$ is country-specific scaling factor implicitly computed from Equation (18), using data on calibrated values of TFP $\left(A_{i}\right)$ and the information on the workforce composition.

As shown in Figure 9, the welfare effects of skill-biased migration are larger once the TFP externality is accounted for, and considerably so at high levels of $\sigma_{a}$. The overall effect on world welfare is of similar size as the effect without the externality, whereas the income inequality between countries is larger. ${ }^{31}$ These results suggest that the baseline simulation results presented in Figure 3 represent a lower bound and that they could be larger in the presence of externalities.

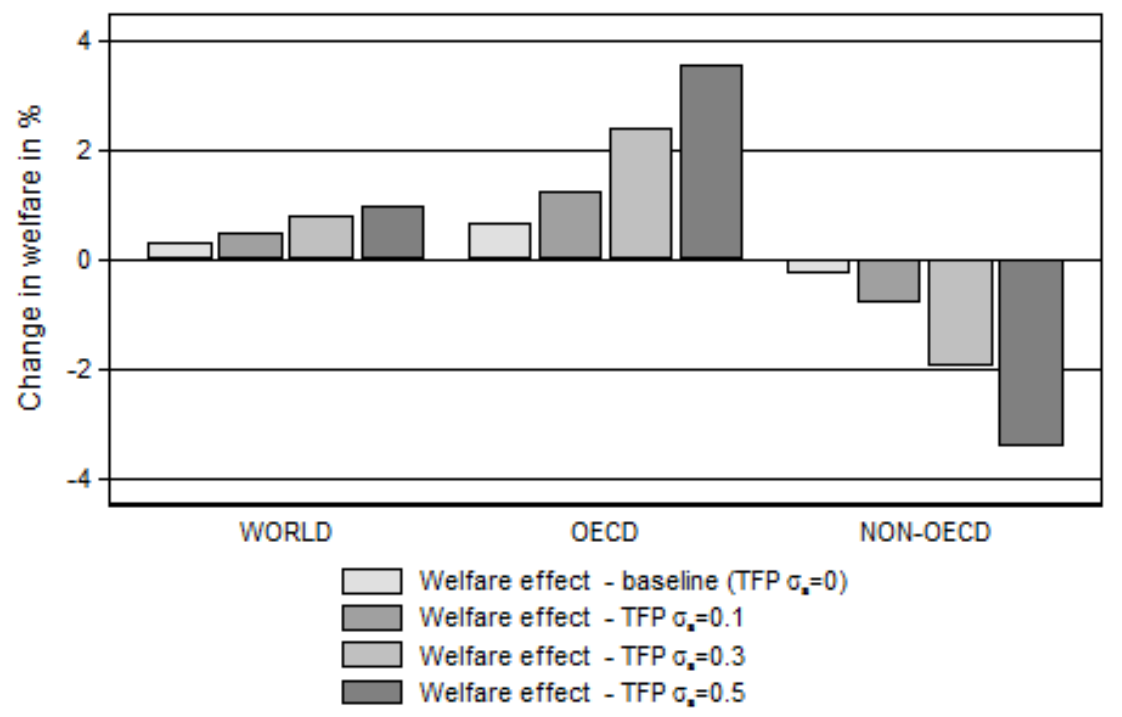

Figure 9: Including Lucas externality on TFP

Source: Own calculations.

Notes: This graph displays the welfare effects of the skill bias in migration with a Lucas-type externality on TFP. We vary the elasticity parameter $\sigma_{a}$. The vertical axis shows changes in welfare per never-migrant in percent.

\subsection{DOWN-SKILLING OF IMMIGRANTS}

As a further sensitivity check, we account for the skill depreciation of migrants in the receiving country. It is common that immigrants - especially those from developing countries - work in jobs for which they are over-qualified (Mattoo et al., 2008). This qualification mismatch might imply that we over-estimate the welfare effects of skill-biased migration in the receiving countries, because replacing a high-skilled with a low-skilled worker may not lead to a change in productivity if both were working in low-skilled jobs to begin with.

between 0.75 and 1.00. de la Croix \& Docquier (2011) use a value of 0.277 .

31 A further - negative - externality through which migration affects TFP in the receiving countries is institutions. As highlighted by Collier (2013) and Borjas (2015), migrants from countries with poor institutions may import these institutions in the receiving country. However, recent work by Clemens \& Pritchett (2016) suggests that large negative effects only unfold under fairly extreme conditions. Moreover, in the receiving countries, the diversity of high-skilled migrants could have an additional effect on TFP. Alesina et al. (2016) find an inverse u-shaped relationship between birthplace diversity and GDP per capita. 
To account for the skill depreciation of immigrants, we compute origin-country-specific down-skilling rates, which measure - for example — the likelihood that a high-skilled Senegalese migrant works in France in a job in which most French workers are low-skilled. Across all sending countries, $29 \%$ of all high-skilled emigrants are working in the OECD in mediumskilled occupations, $10 \%$ in low-skilled occupations and $24 \%$ of all medium-skilled emigrants are working in low-skilled jobs. In Appendix C.3, we explain the construction of these measures in greater detail.

As shown in Figure 10, down-skilling reduces the welfare effects of skill-biased migration in the receiving countries, while leaving the effect in the sending countries unchanged. The global effect is smaller but remains positive at around $0.15 \%$.

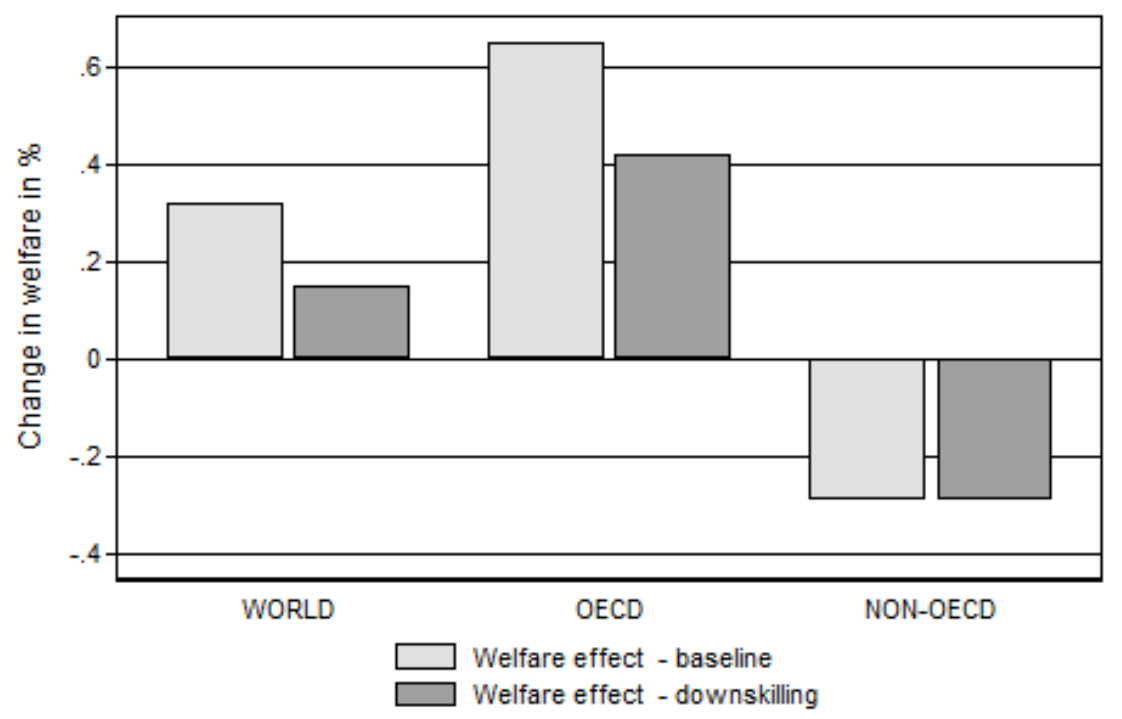

Figure 10: Allowing for down-skilling in the receiving country

Source: Own calculations.

Notes: This graph displays the average welfare effects of the skill bias in migration with down-skilling of migrants. The vertical axis shows changes in welfare per never-migrant in percent.

\subsection{NETWORK EFFECTS IN TRADE}

A growing body of literature shows that immigrants foster trade with their home countries by reducing trade costs and demanding home-country-specific goods (Gould, 1994; Rauch \& Trindade, 2002; Felbermayr \& Toubal, 2012; Egger et al., 2012; Parsons \& Vézina, 2014). For our analysis, this channel is important if trade flows respond to changes in the skill composition; for example, because high-skilled migrants establish better business links. In this case, network effects could add to the overall welfare effect. To assess the importance of skill-biased migration for trade, we simulate two scenarios: one in which trade costs are reduced by high-skilled migrants, and one in which they are reduced by both medium- and high-skilled migrants. We compute trade costs as 


$$
\tau_{i j}=\bar{\tau}_{i j}\left(\frac{H_{i j}}{H_{i j}+M_{i j}+L_{i j}}\right)^{\sigma_{t}}
$$

where $H_{i j}, M_{i j}$ and $L_{i j}$ are the skillspecific stocks of immigrants and $\bar{\tau}_{i j}$ are the bilateral trade costs at baseline. ${ }^{32}$ The parameter $\sigma_{t}$ is the elasticity of trade costs with respect to the skill share of immigrants. To calibrate this elasticity, we use $\sigma_{t}=-0.04$, as estimated by Parsons \& Vézina (2014). Given that this externality is based on immigration, it directly affects the receiving countries. The sending countries — having no immigrants by assumption — can only be indirectly affected through general equilibrium effects.

Figure 11 displays the welfare effects of skill-biased migration with and without network effects in trade. The overall welfare effect in the world is larger when we allow for network effects.

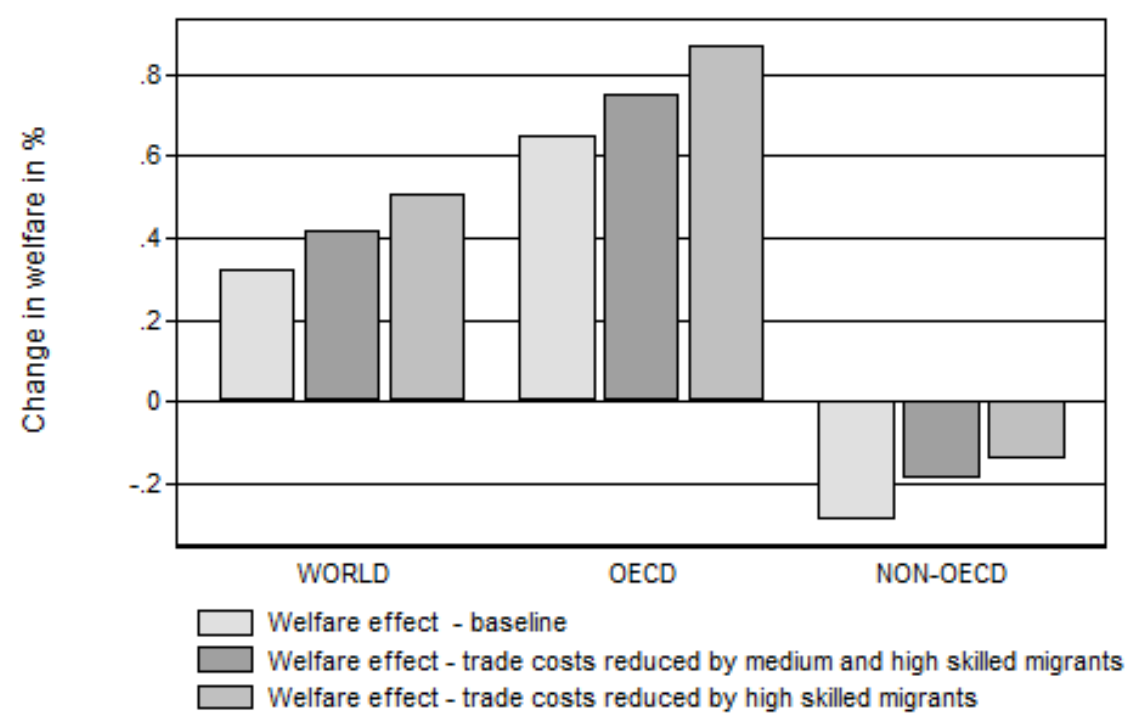

Figure 11: Including network effects of migration on trade

Source: Own calculations.

Notes: This graph displays the welfare effects of the skill bias in migration with network effects of migration on trade. The vertical axis shows changes in welfare per never-migrant in percent.

\subsection{THE ROLE OF TRADE}

In our model, all countries are linked through trade in differentiated goods, which propagates changes in a country's market size across all trading partners, thereby mitigating the domestic welfare effect.

Figure 12 displays the welfare effects with and without trade responses. In the non-OECD

32 In an alternative simulation, we consider trade costs as a function of the share of both high- and mediumskilled workers, i.e. $\tau_{i j}=\bar{\tau}_{i j}\left(\frac{H_{i j}+M_{i j}}{H_{i j}+M_{i j}+L_{i j}}\right)^{\sigma_{t}}$ 
countries, trade makes a difference for the welfare effects. It dampens the negative welfare effect, especially in countries with a high degree of skill bias and a high share of emigrants. In the OECD countries, trade does not account for a large difference in the welfare effects, which suggests that the welfare impact of skill-biased migration is driven by the change in domestic market size rather than the change in trade flows.

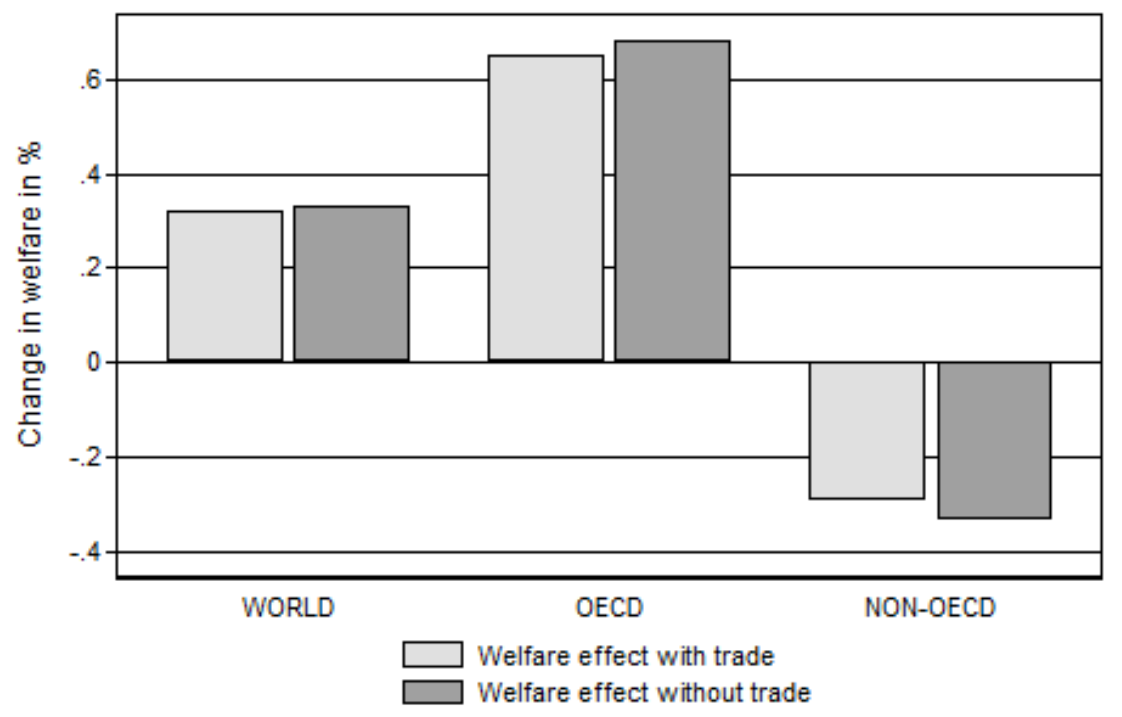

Figure 12: Welfare effects with and without trade

Source: Own calculations.

Notes: This graph shows the role of trade when quantifying the welfare impact of the skill bias in migration.The vertical axis shows changes in welfare per never-migrant in percent.

\subsection{SELECTION VS. SCALE EFFECT}

Thus far, we have found effects of the skill bias in migration on the welfare of never-migrants ranging between 0 and $2 \%$. We now put these estimates into perspective by comparing them with the total welfare impact of migration, namely the welfare difference between migration at its current level and skill composition as well as a world without migration. As shown in Figure 13 , in non-OECD countries the skill bias accounts for one-third of the overall welfare effect of migration. By contrast, in the receiving countries the skill bias in migration only plays a minor role in explaining the overall welfare effect.

\subsection{SELECTION VS. SORTING EFFECT}

Thus far, our baseline results measure the impact of having a migrant from country $x$ with a given skill set and going to country $y$, instead of having a randomly selected person from $x$ going to $y$. Therefore, our estimates measure both the selection effect of migration, that is the fact that migrants have different skills compared with non-migrants, as well as the sorting effect in 


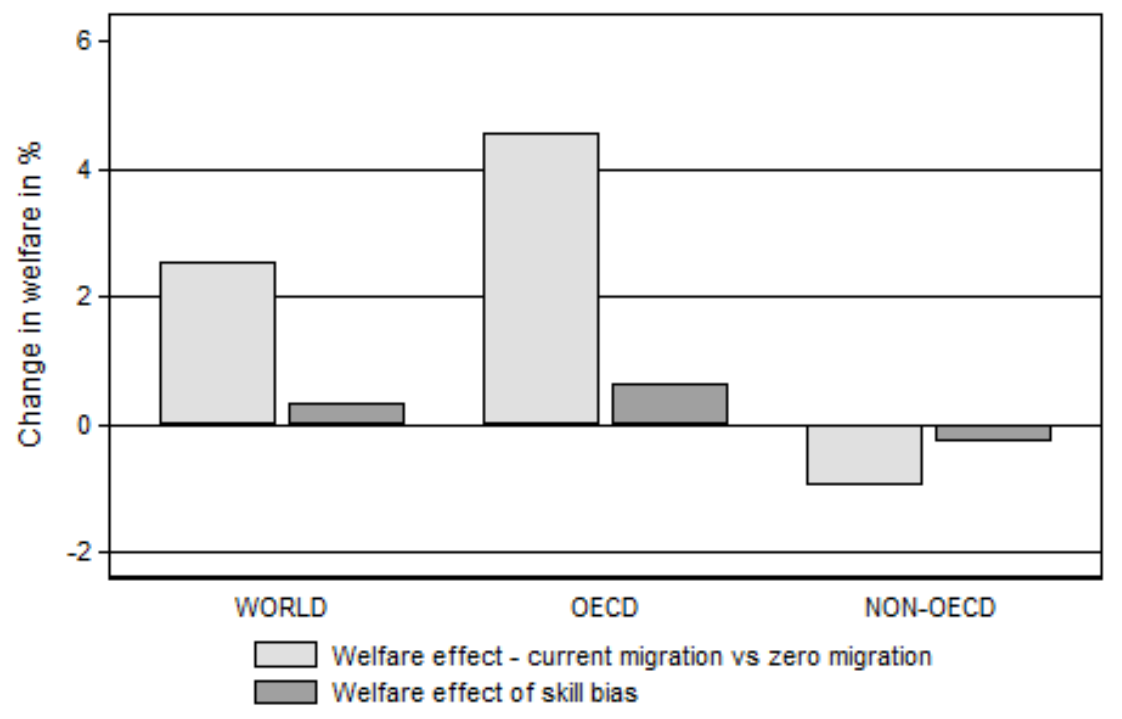

Figure 13: Selection vs. scale effects

Source: Own calculations.

Notes: In this graph, we compare the welfare effect of the skill bias in migration to the welfare impact of migration per se, namely the welfare difference between the status quo and a world without migration. The vertical axis shows changes in welfare per never-migrant in percent.

migration, namely the fact that we observe migrants from $x$ choosing to go to $y$ rather than $z$.

We further contextualize our findings by comparing them to one additional scenario. Rather than randomly selecting migrants for each destination country based on their respective sending countries, we now take all migrants and redistribute them randomly across destinations. This second scenario captures the importance of skill bias in migration while excluding the sorting effect of migrants.

As shown in Figure 14, world welfare would be slightly higher if migrants did not sort into specific destinations but instead were randomly distributed across receiving countries. However, overall this exercise suggests that the selectivity of migration - the question of whether it is more the high-skilled who move to the OECD - is quantitatively more important than the sorting of migrants within the OECD, namely the question of whether the high-skilled go to the US rather than the UK.

\subsection{DISCUSSION AND FURTHER SENSITIVITY CHECKS}

The results in this section show that the baseline results are conservative estimates of the global welfare effect of skill-biased migration. Once we account for remittances, network effects in trade or human capital externalities, the global welfare effect is even higher. The exception here is skill depreciation, which reduces the welfare gains in the receiving countries.

In Appendix D, we also assess the sensitivity of the baseline results to changes in all exogenous parameters of the model. While the magnitude of the effects is affected by changes in the 


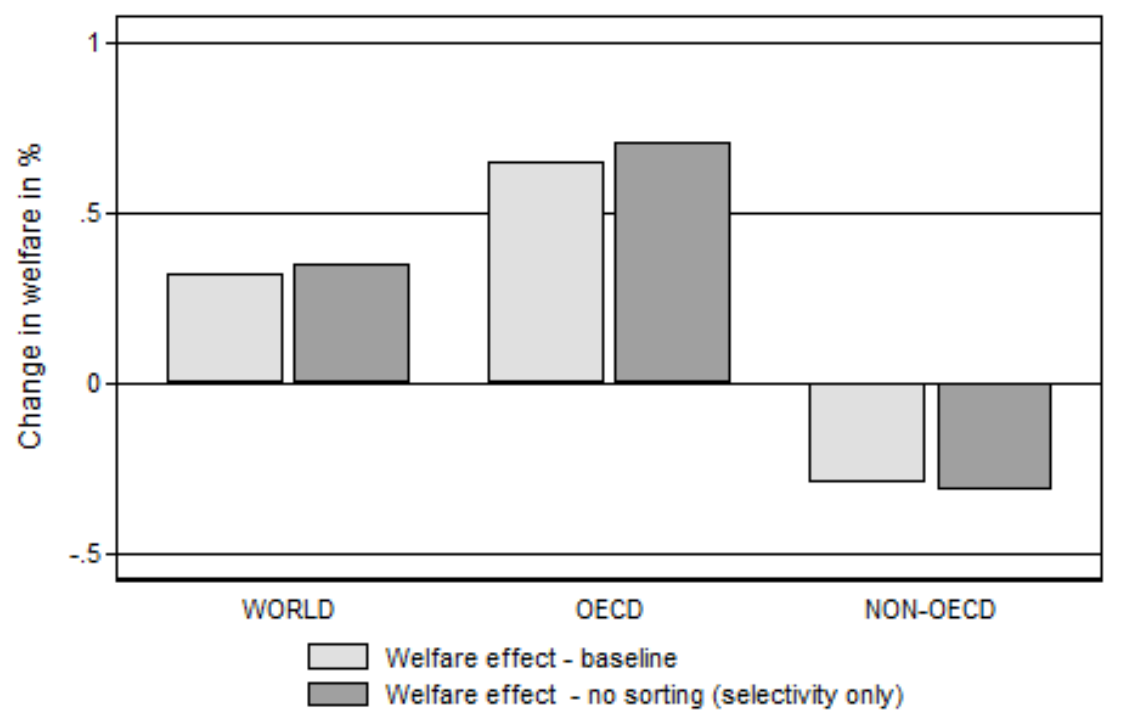

Figure 14: Selection vs. sorting effects

Source: Own calculations.

Notes: In this graph, we compare the welfare effect of selectivity and sorting. The vertical axis shows changes in welfare per never-migrant in percent.

parameters, the qualitative result of positive effects in the receiving countries, negative effects in the sending countries and a positive global welfare effect remains.

\section{ConClusion}

The debate on the welfare consequences of skill-biased migration — the so-called 'brain drain' — has almost exclusively focused on the consequences for the sending countries. In this paper, we provide a global perspective on the brain drain by jointly analyzing its welfare impact on nonmigrants in the sending and receiving countries. For this purpose, we develop a multi-country general equilibrium model and compare the welfare in today's world to a counterfactual with the same number of migrants but without skill bias in migration.

Two central findings emerge from this analysis. First, receiving countries significantly gain from the skill bias in migration. In most OECD countries, the welfare of natives would be around $2 \%$ lower if all migrants were neutrally selected on observable skills from their respective sending countries. Second, skill-biased migration is globally welfare-enhancing. Despite the possibility of welfare losses in the sending countries, these losses are smaller than the gains in the receiving countries. This global welfare gain arises from a more efficient global allocation of talent, because in a world with skill-biased migration a larger number of high-skilled workers live and work in countries where they are most productive.

We further conduct a policy experiment, in which we assume that every OECD country introduces a selective points-based system following the example of Canada. Such a system 
would double the global welfare gains from skill-biased migration, although it would also lead to greater welfare losses in some sending countries. Together, these results suggest that more not less — skill-biased migration would be optimal for global welfare. Moreover, from a global perspective, policies such as migration restrictions or taxes on migrants would be inefficient, because they would reduce global welfare.

This paper opens up several avenues for future research. The policy experiment shows that while a more selective immigration policy leads to global welfare gains, it also exacerbates income inequality between rich and poor countries. However, the impact of migration on global inequality becomes less clear once we consider the welfare of migrants themselves, which have been left out in this paper. We are comfortable calling the welfare effect global because it covers more than $95 \%$ of the world population, namely all non-migrants. But the simulations show that migrants seem to gain considerably. Quantifying the impact of selectivity on the migrants themselves therefore deserves attention. In addition, given that some countries win and others lose while the global gains are positive, it should be possible to design a migration policy that increases the global welfare by encouraging more skill-biased migration, in combination with a scheme in which the winners compensate the losers. 


\section{REFERENCES}

Acemoglu, Daron, \& Angrist, Joshua. 2000. How Large Are Human-Capital Externalities? Evidence from Compulsory Schooling Laws. NBER Macroeconomics Annual, 15, 9-59.

Alesina, Alberto, Harnoss, Johann, \& Rapoport, Hillel. 2016. Birthplace Diversity and Economic Prosperity. Journal of Economic Growth, 21(2), 101-138.

Aubry, Amandine, Burzyński, Michae, \& Docquier, Frédéric. 2016. The Welfare Impact of Global Migration in the OECD Countries. Journal of International Economics, forthcoming.

Barro, Robert J., \& Lee, Jong-Wha. 2010. A New Data Set of Educational Attainment in the World, 1950-2010. NBER Working Paper, 15902.

Batista, Catia, \& Vicente, Pedro C. 2011. Do Migrants Improve Governance at Home? Evidence from a Voting Experiment. World Bank Economic Review, 25(1), 77-104.

Batista, Catia, lacuesta, Aitor, \& Vicente, Pedro C. 2011. Testing the Brain Gain Hypothesis: Micro-Evidence from Cape Verde. Journal of Development Economics, 97(1), $32-45$.

Battisti, Michele, Felbermayr, Gabriel, Peri, Giovanni, \& Poutvaara, Panu. 2014. Immigration, Search, and Redistribution: A Quantitative Assessment of Native Welfare. NBER Working Paper, 20131.

Beine, Michel, Docquier, Fréderic, \& Rapoport, Hillel. 2001. Brain Drain and Economic Growth: Theory and Evidence. Journal of Development Economics, 64, 275-289.

Beine, Michel, Docquier, Fréderic, \& Rapoport, Hillel. 2008. Brain Drain and Human Capital Formation in Developing Countries: Winners and Losers. The Economic Journal, 118, 631-652.

Bernard, Andrew B., Eaton, Johanthan, Jensen, J. Bradford, \& Kortum, Samuel. 2003. Plants and Productivity in International Trade. American Economic Review, 93(4), $1268-1290$.

Bhagwati, Jagdish, \& Hamada, Koichi. 1974. The Brain Drain, International Intergration of Markets for Professionals and Unemployment. Journal of Development Economics, 1(1), $19-42$.

Biavaschi, Costanza, \& Elsner, Benjamin. 2013. Let's Be Selective about Migrant SelfSelection. IZA Discussion Paper, 7865.

Bollard, Albert, McKenzie, David, Morten, Melanie, \& Rapoport, Hillel. 2011. Remittances and the Brain Drain: The Microdata Show that more Educated Migrants Remit more. World Bank Economic Review, 25(1), 132-156. 
Borjas, George J. 1987. Self-Selection and the Earnings of Immigrants. The American Economic Review, 77(4), 531-553.

Borjas, George J. 2003. The Labor Demand Curve IS Downward Sloping: Re-examining the Impact of Immigration on the Labor Market. The Quarterly Journal of Economics, 118(4), $1335-1374$.

Borjas, George J. 2015. Immigration and Globalization: A Review Essay. Journal of Economic Literature, 53(4), 961-974.

Card, David, \& Lemieux, Thomas. 2001. Can Falling Supply Explain the Rising Return to College For Younger Men? A Cohort-Based Analysis. The Quarterly Journal of Economics, $\mathbf{1 1 6}(2), 705-746$.

Chand, Satish, \& Clemens, Michael. 2008. Skilled Emigration and Skill Creation: A Quasi-Experiment. Center for Global Development Working Paper, 152.

Chiswick, BARry R. 1999. Are Immigrants Favorably Self-Selected. The American Economic Review Papers and Proceedings, 89(2), 181-185.

Clemens, Michael A., \& Pritchett, Lant. 2016. The New Economic Case for Migration Restrictions: An Assessment. IZA Discussion Paper, 9730.

Collier, Paul. 2013. Exodus: How Migration is Changing Our World. Oxford University Press.

De la Croix, David, \& Docquier, Frédéric. 2011. Do Brain Drain and Poverty Result from Coordination Failures? Journal of Economic Growth, 17, 1-26.

Delogu, Marco, Docquier, Frédéric, \& Machado, JoëL. 2015. Globalizing Labor and the World Economy: the Role of Human Capital. Université Catholique de Louvain, mimeo.

Di Giovanni, Julian, Levchenko, Andrei A., \& Ortega, Francesc. 2015. A Global View of Cross-Border Migration. Journal of the European Economic Association, 13(1), 168202.

Dinkelman, Taryn, \& Mariotti, Martine. 2016. The Long Run Effects of Labor Migration on Human Capital Formation in Communities of Origin. American Economic Journal: Applied Economics, forthcoming.

Docquier, Frédéric, \& Machado, JoËL. 2015. Global Competition for Attracting Talents and the World Economy. The World Economy, 19(4), 530-542.

Docquier, Frédéric, \& Rapoport, Hillel. 2012a. Globalization, Brain Drain and Development. Journal of Economic Literature, 50(3), 681-730. 
Docquier, Frédéric, \& Rapoport, Hillel. 2012b. Quantifying the Impact of HighlySkilled Emigration on Developing Countries. Chap. II of: Boeri, Tito, Brücker, HerBert, Docquier, Frédéric, \& Rapoport, Hillel (eds), Brain Drain and Brain Gain: The Global Competition to Attract High-Skilled Migrants. Oxford University Press.

Docquier, Frédéric, Özden, ÇaĞLar, \& Peri, Giovanni. 2014. The Wage Effects of Immigration and Emigration. Economic Journal, 129(579), 1106-1145.

Docquier, Frédéric, Machado, Jöel, \& Sekkat, Khalid. 2015a. Efficiency Gains from Liberalizing Labor Mobility. The Scandinavian Journal of Economics, 117(2), 303-346.

Docquier, Frédéric, lodigiani, Elisabetta, Rapoport, Hillel, \& Schiff, Maurice. 2015b. Emigration and Democracy. Journal of Development Economics, 120, 209-223.

Dustmann, Christian, Frattini, Tommaso, \& Preston, Ian P. 2013. The Effect of Immigration along the Distribution of Wages. The Review of Economic Studies, 80, 145-173.

Eaton, Johanthan, Kortum, Samuel, \& Kramarz, Francis. 2011. An Anatomy of International Trade: Evidence from French Firms. Econometrica, 79(5), 1453-1498.

Egger, Peter H., von Ehrlich, Maximilian, \& Nelson, Douglas R. 2012. Migration and Trade. The World Economy, 35(2), 216-241.

Faini, Riccardo. 2007. Remittances and the Brain Drain: Do more Skilled Migrants Remit more? The World Bank Economic Review, 21(2), 177-191.

Felbermayr, Gabriel, \& Toubal, Farid. 2012. Revisiting the Trade-Migration Nexus: Evidence from New OECD Data. World Development, 40(5), 928-937.

Felbermayr, Gabriel J., \& Kohler, Wilhelm. 2007. Immigration and Native Welfare. International Economic Review, 48(3), 731-760.

Gould, David M. 1994. Immigrant Links to the Home Country: Empirical Implications for U.S. Bilateral Trade Flows. Review of Economics \& Statistics, 76(2), 302-316.

Hamilton, Bob, \& Whalley, John. 1984. Efficiency and Distributional Implications of Global Restrictions on Labour Mobility: Calculations and Policy Implications. Journal of Development Economics, 14(1-2), 61-75.

Head, Keith, \& Mayer, Thierry. 2015. Gravity Equations: Workhorse,Toolkit, and Cookbook. Pages 131-195 of: Gopinath, Gita, Helpman, Elhanan, \& Rogoff, Kenneth (eds), Handbook of International Economics, vol. 4. Elsevier.

Iranzo, Susana, \& Peri, Giovanni. 2009. Migration and Trade: Theory with an Application to the Eastern-Western European Integration. Journal of International Economics, 79, 1-19.

Kennan, John. 2013. Open Borders. Review of Economic Dynamics, 16(2), L1-L13. 
Klein, Paul, \& Ventura, Gustavo. 2007. TFP Differences and the Aggregate Effects of Labor Mobility in the Long Run. B.E. Journals in Macroeconomics, 7(1).

Klein, Paul, \& Ventura, Gustavo. 2009. Productivity Differences and the Dynamics of International Labour Movements. Journal of Monetary Economics, 56, 1059-1073.

Krugman, Paul. 1980. Scale Economies, Product Differentiation, and the Pattern of Trade. American Economic Review, 70(5), 950-959.

Lucas, Robert E. 1988. On the Mechanics of Economic Development. Journal of Monetary Economics, 22, 3-42.

Mahmoud, Toman Omar, Rapoport, Hillel, Steinmayr, Andreas, \& Trebesch, Christoph. 2014. The Effect of Labor Migration on the Diffusion of Democracy: Evidence from a Former Soviet Republic. IZA Discussion Paper, 7980.

Mattoo, Aaditya, Neagu, Ileana Cristina, \& Çă̆lar Özden. 2008. Brain Waste? Educated Immigrants in the US Labor Market. Journal of Development Economics, 255-269.

Mayer, Thierry, Head, Keith, \& Ries, John. 2010. The Erosion of Colonial Trade Linkages after Independence. Journal of International Economics, 81(1), 1-14.

Moretti, Enrico. 2004a. Estimating the Social Return to Higher Education: Evidence from Longitudinal and Repeated Cross-sectional Data. Journal of Econometrics, 121, 175-212.

Moretti, Enrico. 2004b. Workers' Education, Spillovers, and Productivity: Evidence from Plant-Level Production Functions. The American Economic Review, 94(3), 656-690.

Mountford, Andrew. 1997. Can a Brain Drain be Good for Growth in the Source Economy? Journal of Development Economics, 53, 287-303.

Nimi, Yoko, Ozden, Caglar, \& Schiff, Maurice. 2008. Remittances and the Brain Drain: Skilled Migrants do Remit less. IZA Discussion Paper, 3393.

OECD. 2010. Education at a Glance. Tech. rept. Organisation for Economic Co-operation and Development (OECD).

Ottaviano, Gianmarco, \& Peri, Giovanni. 2012. Rethinking the Effects of Immigration on Wages. Journal of the European Economic Association, 10(1), 152-197.

Parro, Fernando. 2013. Capital-Skill Complementarity and the Skill Premium in a Quantitative Model of Trade. American Economic Journal: Macroeconomics, 5(2), 72-117.

Parsons, Christopher, \& Vézina, Pierre-Louis. 2014. Migrant Networks and Trade: The Vietnamese Boat People as a Natural Experiment. University of Oxford, mimeo.

Peri, Giovanni, \& Sparber, Chad. 2009. Task Specialization, Immigration and Wages. American Economic Journal: Applied Economics, 1(3), 135-169. 
Rauch, James E., \& Trindade, Vitor. 2002. Ethnic Chinese Networks in International Trade. Review of Economics and Statistics, 84(1), 116-130.

Shrestha, Slesh A. 2015. No Man Left Behind: Effects of Emigration Prospects on Educational and Labour Outcomes of Non-migrants. Economic Journal, forthcoming.

Simonovska, Ina, \& Waugh, Michael E. 2014. The Elasticity of Trade: Estimates and Evidence. Journal of International Economics, 92(1), 34-50.

Stark, Oded, Helmenstein, Christian, \& Prskawetz, Alexia. 1997. A Brain Gain with a Brain Drain. Economics Letters, 55, 227-234.

Trefler, Daniel. 1993. International Factor Price Differences: Leontief was Right! The Journal of Political Economy, 101(6), 961-987.

Vidal, JeAn-Pierre. 1998. The Effect of Emigration on Human Capital Formation. Journal of Population Economics, 11, 589-600.

Yang, Dean. 2008. International Migration, Remittances and Household Investment: Evidence from Philippine Migrants' Exchange Rate Shocks. The Economic Journal, 118, 591-630. 


\section{Online Appendices}

(Not for publication)

A Theoretical model - components 42

A.1 Indirect utility . . . . . . . . . . . . . . . . . . . . 42

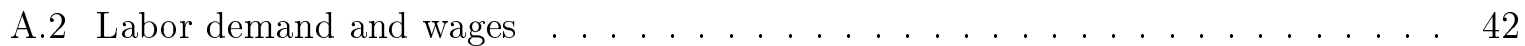

A.3 Market clearing conditions . . . . . . . . . . . . . . . . . . . 43

A.4 Definition of equilibrium . . . . . . . . . . . . . . . . . 44

B Calibration and simulation $\quad \mathbf{4 5}$

B.1 Classification of skill groups . . . . . . . . . . . . . . . . . . . . . 45

B.2 Imputation of trade flows . . . . . . . . . . . . . . . . . . . . 45

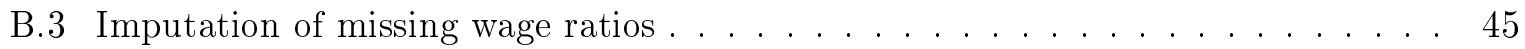

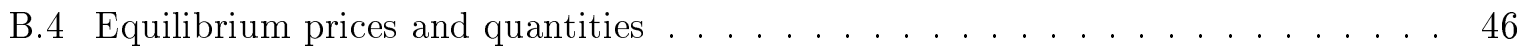

B.5 Simulation algorithm . . . . . . . . . . . . . . . . 46

$\begin{array}{ll}\text { C Extensions } & 47\end{array}$

C.1 Remittances . . . . . . . . . . . . . . . . . . . . . . . . . 47

C.2 Brain Gain . . . . . . . . . . . . . . . . . . . . . . . 48

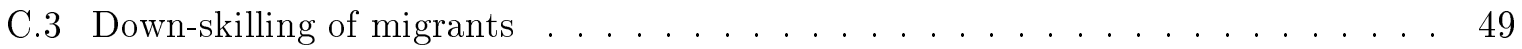

$\begin{array}{ll}\text { D Sensitivity checks } & 50\end{array}$

E List of abbreviations and Full Baseline Results $\quad 54$ 


\section{A Theoretical MODEL - COMPONENTS}

This section provides a detailed description of the theoretical model that has been summarized in Section 3.

\section{A.1 IndiReCt UTiLity}

After maximizing utility subject to the budget constraint (Equation (1)), the individual demands for all types of consumption goods are as follows:

$$
\begin{aligned}
T_{i}^{s} & =\left(\frac{\beta^{T} \mu}{1-\beta^{T}} \frac{P_{i}}{P_{i}^{T}}\right)^{\frac{1}{1-\mu}}, \\
Y_{i}^{s} & =\left(w_{i}^{s}-T_{i}^{s}\right)(1-\beta)^{\theta}\left(P_{i}\right)^{\theta-1}\left(P_{i}^{Y}\right)^{-\theta}, \\
X_{i}^{s} & =\left(w_{i}^{s}-T_{i}^{s}\right) \beta^{\theta}\left(P_{i}\right)^{\theta-1}\left(P_{i}^{X}\right)^{-\theta} \\
x_{i j}^{s} & =\left(w_{i}^{s}-T_{i}^{s}\right) \beta^{\theta}\left(P_{i}\right)^{\theta-1}\left(P_{i}^{X}\right)^{\varepsilon-\theta}\left(p_{i j}\right)^{-\varepsilon}, \\
y_{i}^{s} & =\left(w_{i}^{s}-T_{i}^{s}\right)(1-\beta)^{\theta}\left(P_{i}\right)^{\theta-1}\left(P_{i}^{Y}\right)^{\varepsilon-\theta}\left(p_{i}\right)^{-\varepsilon} .
\end{aligned}
$$

The demand for the traditional good is the same for all individuals in country $i$, and is independent of their real wage. This follows from the assumption of non-homothetic preferences. Consumption of these goods can be seen as expenditure that is necessary for survival. Once consumers have more income, they spend a greater share of their income on differentiated goods. Thus, the relative demand for the goods $X$ and $Y$ increases with income.

Inserting the demands (20) into the utility function (1), we obtain an agent's indirect utility,

$$
U_{i}^{s}=\beta^{T}\left(\frac{\beta^{T} \mu}{1-\beta^{T}} \frac{P_{i}}{P_{i}^{T}}\right)^{\frac{\mu}{1-\mu}}+\left(1-\beta^{T}\right) \frac{w_{i}^{s}-T_{i}^{s}}{P_{i}} .
$$

\section{A.2 LABOR DEMAND AND WAGES}

The production functions of the traditional and the manufacturing sector are

$$
\begin{aligned}
Q_{i}^{T} & =A_{i}^{T} L_{i}^{T} \\
Q_{i}^{M}=A_{i}^{M} L_{i}^{M} & =A_{i}^{M}\left[\alpha_{i}^{L}\left(L_{i}\right)^{\frac{\sigma_{s}-1}{\sigma_{s}}}+\left(1-\alpha_{i}^{L}-\alpha_{i}^{H}\right)\left(M_{i}\right)^{\frac{\sigma_{s}-1}{\sigma_{s}}}+\alpha_{i}^{H}\left(H_{i}\right)^{\frac{\sigma_{s}-1}{\sigma_{s}}}\right]^{\frac{\sigma_{s}}{\sigma_{s}-1}} .
\end{aligned}
$$

where $L_{i}^{T}$ is the supply of low-skilled labor employed in the traditional sector, and $A_{i}^{T}$ is the productivity residual, which equals the wage rate of the low-skilled workers over the price level in $T: A_{i}^{T}=W_{i}^{L} / P_{i}^{T} \cdot{ }^{33} L_{i}, M_{i}$ and $H_{i}$ represent the supplies of low-, medium- and high-skilled workers in the manufacturing sector. The parameters $\alpha_{i}^{L}$ and $\alpha_{i}^{H}$ indicate, respectively, the efficiency of low- and medium-skilled workers in production. Each skill group consists of natives (labeled by superscripts $N$ ) and foreigners (with superscripts $F$ ). All domestic and foreign workers are assumed to be imperfect substitutes with a constant elasticity of substitution equal

\footnotetext{
33 This wage is equal across sectors and across workers' origin. Therefore, any low-skilled worker from $T$ sector has no incentives to move to $X$ and $Y$ sectors.
} 
to $\sigma_{n}$. We define the efficient labor supplies for each sector and education group as

$$
\begin{aligned}
L_{i}^{T} & =\left[\left(1-\alpha_{i}^{F}\right)\left(L_{i}^{T, N}\right)^{\frac{\sigma_{n}-1}{\sigma_{n}}}+\alpha_{i}^{F}\left(L_{i}^{T, F}\right)^{\frac{\sigma_{n}-1}{\sigma_{n}}}\right]^{\frac{\sigma_{n}}{\sigma_{n}-1}}, \\
L_{i} & =\left[\left(1-\alpha_{i}^{F}\right)\left(L_{i}^{N}\right)^{\frac{\sigma_{n}-1}{\sigma_{n}}}+\alpha_{i}^{F}\left(L_{i}^{F}\right)^{\frac{\sigma_{n}-1}{\sigma_{n}}}\right]^{\frac{\sigma_{n}}{\sigma_{n}-1}} \\
M_{i} & =\left[\left(1-\alpha_{i}^{F}\right)\left(M_{i}^{N}\right)^{\frac{\sigma_{n}-1}{\sigma_{n}}}+\alpha_{i}^{F}\left(M_{i}^{F}\right)^{\frac{\sigma_{n}-1}{\sigma_{n}}}\right]^{\frac{\sigma_{n}}{\sigma_{n}-1}}, \\
H_{i} & =\left[\left(1-\alpha_{i}^{F}\right)\left(H_{i}^{N}\right)^{\frac{\sigma_{n}-1}{\sigma_{n}}}+\alpha_{i}^{F}\left(H_{i}^{F}\right)^{\frac{\sigma_{n}-1}{\sigma_{n}}}\right]^{\frac{\sigma_{n}}{\sigma_{n}-1}} .
\end{aligned}
$$

We assume a fixed, country-specific share of outputs of natives and foreigners $\left(\left(1-\alpha_{F}\right)\right.$ and $\alpha_{F}$ respectively).

Firms solve their cost-minimization problem, taking wages as given. Demand for each type of labor is then set as

$$
\begin{array}{lll}
L_{i}^{N} & =\frac{Q_{i}^{M}}{A_{i}^{M}}\left[\frac{\left(1-\alpha_{i}^{F}\right) W_{i}^{L}}{w_{i}^{L N}}\right]^{\sigma_{n}}\left[\frac{\alpha_{i}^{L} W_{i}}{W_{i}^{L}}\right]^{\sigma_{s}}, & L_{i}^{T, N}=\frac{Q_{i}^{T}}{A_{i}^{T}}\left[\frac{\left(1-\alpha_{i}^{F}\right) W_{i}^{L}}{w_{i}^{L N}}\right]^{\sigma_{n}}, \\
L_{i}^{F}=\frac{Q_{i}^{M}}{A_{i}^{M}}\left[\frac{\alpha_{i}^{F} W_{i}^{L}}{w_{i}^{L F}}\right]^{\sigma_{n}}\left[\frac{\alpha_{i}^{L} W_{i}}{W_{i}^{L}}\right]^{\sigma_{s}}, & L_{i}^{T, F}=\frac{Q_{i}^{T}}{A_{i}^{T}}\left[\frac{\alpha_{i}^{F} W_{i}^{L}}{w_{i}^{L F}}\right]^{\sigma_{n}}, \\
M_{i}^{N}=\frac{Q_{i}^{M}}{A_{i}^{M}}\left[\frac{\left(1-\alpha_{i}^{F}\right) W_{i}^{M}}{w_{i}^{M N}}\right]^{\sigma_{n}}\left[\frac{\left(1-\alpha_{i}^{H}-\alpha_{i}^{L}\right) W_{i}}{W_{i}^{M}}\right]^{\sigma_{s}}, H_{i}^{N}=\frac{Q_{i}^{M}}{A_{i}^{M}}\left[\frac{\left(1-\alpha_{i}^{F}\right) W_{i}^{H}}{w_{i}^{H N}}\right]^{\sigma_{n}}\left[\frac{\alpha_{H} W_{i}}{W_{i}^{H}}\right]^{\sigma_{s}}, \\
M_{i}^{F}=\frac{Q_{i}^{M}}{A_{i}^{M}}\left[\frac{\alpha_{i}^{F} W_{i}^{M}}{w_{i}^{M F}}\right]^{\sigma_{n}}\left[\frac{\left(1-\alpha_{H}-\alpha_{i}^{L}\right) W_{i}}{W_{i}^{M}}\right]^{\sigma_{s}}, & H_{i}^{F}=\frac{Q_{i}^{M}}{A_{i}^{M}}\left[\frac{\alpha_{i}^{F} W_{i}^{H}}{w_{i}^{H F}}\right]^{\sigma_{n}}\left[\frac{\alpha_{H} W_{i}}{W_{i}^{H}}\right]^{\sigma_{s}},
\end{array}
$$

where the wage indices for the medium- and high-skilled workers are equal to:

$$
\begin{aligned}
& W_{i}^{L}=\left[\left(1-\alpha_{i}^{F}\right)^{\sigma_{n}}\left(w_{i}^{L N}\right)^{1-\sigma_{n}}+\left(\alpha_{i}^{F}\right)^{\sigma_{n}}\left(w_{i}^{L F}\right)^{1-\sigma_{n}}\right]^{\frac{1}{1-\sigma_{n}}}, \\
& W_{i}^{M}=\left[\left(1-\alpha_{i}^{F}\right)^{\sigma_{n}}\left(w_{i}^{M N}\right)^{1-\sigma_{n}}+\left(\alpha_{i}^{F}\right)^{\sigma_{n}}\left(w_{i}^{M F}\right)^{1-\sigma_{n}}\right]^{\frac{1}{1-\sigma_{n}}}, \\
& W_{i}^{H}=\left[\left(1-\alpha_{i}^{F}\right)^{\sigma_{n}}\left(w_{i}^{H N}\right)^{1-\sigma_{n}}+\left(\alpha_{i}^{F}\right)^{\sigma_{n}}\left(w_{i}^{H F}\right)^{1-\sigma_{n}}\right]^{\frac{1}{1-\sigma_{n}}},
\end{aligned}
$$

and the overall wage index in the manufacturing sector is given by:

$$
W_{i}=\left[\left(\alpha_{i}^{L}\right)^{\sigma_{s}}\left(W_{i}^{L}\right)^{1-\sigma_{s}}+\left(1-\alpha_{i}^{L}-\alpha_{i}^{H}\right)^{\sigma_{s}}\left(W_{i}^{M}\right)^{1-\sigma_{s}}+\left(\alpha_{i}^{H}\right)^{\sigma_{s}}\left(W_{i}^{H}\right)^{1-\sigma_{s}}\right]^{\frac{1}{1-\sigma_{s}}} .
$$

\section{A.3 MARKET ClEARING CONDitions}

Since all firms earn zero profits, the total wage bill must equal the value added produced in all sectors:

$$
\begin{aligned}
G D P_{i}^{T} & =W_{i}^{L} L_{i}^{T}=w_{i}^{L N} L_{i}^{T, N}+w_{i}^{L F} L_{i}^{T, F}, \\
G D P_{i}^{X}+G D P_{i}^{Y} & =W_{i} L_{i}^{M}= \\
& =w_{i}^{L}\left(L_{i}^{N}+L_{i}^{F}\right)+w_{i}^{M N} M_{i}^{N}+w_{i}^{M F} M_{i}^{F}+w_{i}^{H N} H_{i}^{N}+w_{i}^{H F} H_{i}^{F} .
\end{aligned}
$$

In equilibrium, when demand equals the value of production, the total value-added in the traditional sector equals the expenditures: $G D P_{i}^{T}=P_{i}^{T} A_{i}^{T} L_{i}^{T}$. Furthermore, in the tradable and non-tradable manufacturing sectors the value-added equals the aggregated value of production 
of all $N_{i}^{X}$ and $N_{i}^{Y}$ firms:

$$
\begin{aligned}
& G D P_{i}^{X}=N_{i}^{X} \sum_{j=1}^{J} p_{j i} x_{j i}=N_{i}^{X} p_{i} x_{i}, \\
& G D P_{i}^{Y}=N_{i}^{Y} p_{i} y_{i} .
\end{aligned}
$$

where $x_{j i}$ is the demand in country $j$ for a product of any firm operating in sector $X$ in country $i$. For simplicity, we aggregate this quantity into one number, namely the total demand for the products of one firm in country $i: x_{i}=\sum_{j=1}^{J} \tau_{j i} x_{j i}$. Due to the iceberg trade costs, in order to sell $x_{j i}$ units in country $j$, the firm from country $i$ has to ship $\tau_{j i} x_{j i}$ units of this good (with $\left.\tau_{j i} \geq 1\right)$.

The aggregation of the values of agents' individual demands gives the level of nominal GDP in country $i$ (equivalent to the sum of all expenditure):

$$
G D P_{i}=G D P_{i}^{T}+G D P_{i}^{X}+G D P_{i}^{Y}=P_{i}^{T} T_{i}+P_{i}^{Y} Y_{i}+P_{i}^{X} X_{i}
$$

Consequently, the share of value-added produced in the traditional sector is equal to:

$$
s h_{T} \equiv \frac{G D P_{i}^{T}}{G D P_{i}}=\frac{P O P_{i}}{G D P_{i}}\left(\frac{\beta^{T} \mu}{1-\beta^{T}} \frac{P_{i}}{P_{i}^{T}}\right)^{\frac{1}{1-\mu}},
$$

where $P O P_{i}$ stands for the number of people living in country $i$ (since every person consumes the same amount of good $T) .{ }^{34}$ The remainder of GDP is spent on the differentiated good. We provide expressions for the shares of goods $X$ and $Y$ in Section 3.4. Based on $s h_{Y}$ and $s h_{X}$, we derive the optimal number of varieties in equilibrium using the zero-profit and free-entry conditions.

\section{A.4 Definition of EQUilibrium}

Definition 1 For a set $\left\{\beta, \beta^{T}, \theta, \mu, \varepsilon, \sigma_{s}, \sigma_{n},\right\}$ of structural parameters, a set $\left\{A_{i}^{T}, A_{i}^{M} \alpha_{i}^{F}, \alpha_{i}^{H}\right.$, $\alpha_{i}^{L}, L_{i}^{T, N}, L_{i}^{T, F}$,

$\left.L_{i}^{N}, L_{i}^{F}, M_{i}^{N}, M_{i}^{F}, H_{i}^{N}, H_{i}^{F}, f_{i}^{X}, f_{i}^{Y}\right\}_{\forall i}$ of country-specific institutional, demographic and technological, exogenous characteristics, a set $\left\{\tau_{j i}\right\}_{\forall i, j}$ of bilateral trade costs

- consumption of the three types of goods $\left\{x_{i j}^{s}, y_{i}^{s}, T_{i}^{s}\right\}$ maximizes an agent's utility (1) subject to the budget constraint,

- assuming full employment and cost-minimizing behavior of firms, the labor market clearing conditions (23) equalize the wage rates to marginal productivities, and determine the nominal wages for all types of workers: $\left\{w_{i}^{L N}, w_{i}^{L F}, w_{i}^{M N}, w_{i}^{M F}, w_{i}^{H N}, w_{i}^{H F}\right\}$

- the price of one variety, $p_{i}(k)$, maximizes firm's profits given the demand that it faces (8),

- the price of a unit of traditional good, $P_{i}^{T}$, equals the marginal productivity of a low-skilled worker in (8),

34 Total population has the following structure: $P O P_{i}=L_{i}^{T, N}+L_{i}^{T, F}+L_{i}^{N}+L_{i}^{F}+M_{i}^{N}+M_{i}^{F}+H_{i}^{N}+H_{i}^{F}$. The low-skilled natives and foreigners are divided into those who work in the traditional sector and those who are employed in the differentiated good sector. The medium- and high-skilled workers are only employed in the $Y$ and $X$ sectors. 
- the number of varieties in sector $X$ and $Y, N_{i}^{X}$ and $N_{i}^{Y}$, is such that the zero-profit conditions hold (13),

- the value-added equals the aggregated value of production and trade in $X$ is balanced.

\section{B Calibration AND Simulation \\ B.1 Classification OF SKILl GROUPS}

Table 2 provides some details about the aggregation of skill groups in both datasets.

Table 2: Classification of skill groups

\section{DIOC}

\begin{tabular}{lll}
\hline Low-skilled & No schooling & No schooling \\
& Some primary education & Some primary education \\
& Completed primary education & Completed primary education \\
& Lower secondary education & Non-completed secondary education \\
Medium-skilled & (Upper) secondary education & Completed secondary education \\
& Post-secondary non-tertiary education & \\
\multirow{2}{*}{ High-skilled } & First stage of tertiary education & Tertiary education \\
& Second stage of tertiary education & (Non-completed and completed) \\
\hline
\end{tabular}

Note: This table details the classification of skill groups in Barro \& Lee (2010) and DIOC.

\section{B.2 IMPUTATION OF TRADE FLOWS}

To compute the bilateral trade costs, we require a $(146 \times 146)$ matrix of gross trade flows between all countries in the sample (145 countries plus the Rest of the World). The UN Comtrade database provides information to fill $66.5 \%$ of all entries of this matrix, whereas the remaining trade flows are missing. Because we require every trade flow to be non-negative for computational purposes, we impute the missing trade flows based on a gravity equation. We first fit the following linear fixed-effect regression on all observed trade flows:

$$
\ln (\text { trade })_{o d}=\boldsymbol{X}_{\text {od }}^{\prime} \gamma+\delta_{o}+\delta_{d}+\varepsilon_{o d}
$$

where index $o$ denotes the origin and $d$ the destination of a trade flow. $\boldsymbol{X}_{\boldsymbol{o d}}$ is a vector of dyad-specific determinants of trade flows, and includes: a common border dummy, a dummy for a common official language, the log distance between the capital cities, a dummy for a common colonial past. These data are taken from the CEPII Gravity dataset (Mayer et al., 2010; Head \& Mayer, 2015). $\varepsilon_{o d}$ is an i.i.d error term. $\delta_{o}$ and $\delta_{d}$ are origin and destination fixed effects. Based on the fitted values, we then predict the trade flows for all remaining dyads.

\section{B.3 IMPUTATION OF MISSING WAGE RATIOS}

The two country-specific wage ratios (high-skilled to medium-skilled and medium-skilled to lowskilled) are obtained as follows. For the 34 OECD countries, the wage ratios are provided by the "OECD Education at a Glance" report 2010 (OECD, 2010). The WageIndicator Foundation 
provides information on 38 additional high-skill to medium-skill and 27 medium-skill to lowskill wage ratios. For the remaining countries, we construct wage ratios as a function of the average return of one additional year of schooling ${ }^{35}(\lambda)$ and the difference in years of schooling $(d)$ between two education levels $(\mathrm{k}, \mathrm{m})$

$$
w_{i}^{k} / w_{i}^{m}=\left(1+\lambda_{k m}\right)^{d},
$$

using data from Barro \& Lee (2010).

\section{B.4 EqUiLIBRIUM PRICES AND QUANTITIES}

In this section, we explain how we calibrate the free parameters of the model and compute equilibrium prices and quantities. The calibration of bilateral trade flows depends on goods prices in each country, which are a function of TFP levels and bilateral trade costs. For a given matrix of bilateral trade costs, the combination of the zero-profit condition and the expression of units produced per firm in Equation (12) yield the level of country- specific TFP in the manufacturing sector. Based on the TFP level, we can assess the marginal cost of production and recover all prices and price aggregates from Equations (4) and (8). Combining these with trade costs allows us to assess the value of bilateral trade flows. For this purpose, we use the gravity equation (16) to iterate over TFP and trade costs until the trade flows in the model match the trade flows in the data as closely as possible.

The iterative procedure is carried out in two steps. We first define an outer loop in which the trade cost matrix $\left[\tau_{j i}\right]_{j, i \in J}$ is determined iteratively, based on the gravity Equation (16). In each iteration, a new matrix of $\tau$ 's is computed from the gravity equation. A new general equilibrium is then obtained by iterating on $A_{i}^{M}$ (i.e. the inner loop) until the distance between the trade matrix from the data and the trade matrix in the model is minimized. The inner loop takes trade costs as given, and iterates on the TFP in the manufacturing sector, $A_{i}^{M}$, such that the zero-profit conditions are fulfilled for firms in all the countries at the same time (and hence the general equilibrium is guaranteed). The iteration uses the whole vector of country-specific TFP in the manufacturing sector, $A_{i}^{M}$, because profits in country $i$ are dependent on the prices of goods in all other countries $\left(P_{i}\right.$ in Equation (4) is a weighted sum of prices of all imported goods, and hence depends on the trade costs defined in the previous step of the outer loop). Once we obtained the vector of TFP, we use the trade costs along with the equilibrium conditions (11) and (12) to compute the vectors of unit prices $p_{i}$, and the price indexes, $P i^{X}$ and $P i^{Y}$, for both sectors.

To compute the fixed cost of entry for the non-tradable manufacturing sector, we first compute the equilibrium number of varieties produced in sector $Y, N_{i}^{Y}$, given the price level $P i^{Y}$. We then back out the fixed cost $f_{i}^{Y}$ from Equation (13) to match the number of varieties. The last parameter to be calibrated is the preference towards goods produced in the traditional sector, $\beta^{T}$. Its value of 0.139 is such that we match consumption of the traditional good to its production.

\section{B.5 Simulation ALGORITHM}

To simulate the counterfactual scenario, we impose an exogenous shock (on the skill structure of migrants) to the general equilibrium of the system of $J$ economies. We then need to compute new wages, price indices and values of production in all sectors. The first equilibrium to compute is in the market for the traditional good. Equalizing its demand and supply in all countries, we

$\overline{35} \quad$ These are assessed based on the countries for which wage ratios and average years of education are available. 
can compute first guesses of the number of people who work in agriculture, and the wage levels of low-skilled workers. Then, taking the first guess on the GDP levels in manufacturing sector, we compute the wage indices (using the system of $J$ zero-profit equations in sectors $X$ and $Y$ ). However, we have no information about the shares of $G D P^{X}$ and $G D P^{Y}$ in manufacturing (which are driven by peoples' preferences towards different varieties of products and prices). Thus, we make an initial guess of the variable $s h^{X}$ - on which we iterate - to meet the definitions of price indices and numbers of varieties (equations (4), and (13)). Additionally, according to the current value of $s h^{X}$, we calculate the price indices, numbers of varieties and GDPs in $X$ and $Y$. With a new guess for $s h^{X}$ we return to the outer loop and re-compute the equilibrium wage for the low-skilled workers and $G D P^{T}$, using the $T$ market clearing condition.

Having pinned down the nominal wage of low-skilled workers and the values of GDPs in all sectors, we can calculate the exact wage index in the manufacturing sector and the wages of all types of workers (using the system of labor demand equations, (23)). Now, unlike in the calibration procedure, the wage premium between high-/medium-skilled and medium-/lowskilled workers is endogenous and determined by the skill composition of the workforce.

Once again, the final step is compute the endogenously determined trade matrix for the given levels of $G D P^{X}$, price indexes and (taken as given) trade costs. Using the system of gravity equations (16), we are able to determine all the bilateral trade flows across $J$ countries.

\section{Extensions \\ C.1 Remittances}

To include remittances in the model, we assume that the fraction of income remitted by the emigrants is exogenous, and is country-pair-specific. To measure remittances, we use bilateral data on the volume of remittances from the World Bank (2015). Formally, the income after remittances $\left(\hat{w_{i j}^{s}}\right)$ of an emigrant of skill type $s$ from country $o$ in receiving country $d$ becomes:

$$
\hat{w_{o d}^{s}}=w_{o d}^{s}\left(1-\eta_{o d}\right)
$$

where $\left(w_{o d}^{s}\right)$ is the wage income before remittances and $\left(\eta_{o d}\right)$ is the fraction of income remitted. This fraction is assessed using data on the volume of bilateral remittances flowing from country $d$ to country o, denoted $R E M I T_{d o}$. Thus,

$$
R E M I T_{d o}=\sum_{s=L, M, H} N_{o d}^{s} w_{o d}^{s} \eta_{o d}
$$

where $N_{o d}^{s}$ is the number of emigrants with skill $s$ from country $o$ living in $d$. The fraction of income remitted $\left(\eta_{o d}\right)$ can then be recovered using Equation (33) with data on REMIT $T_{d o}$ and the emigration matrix $\left(N_{o d}^{s}\right)$ and the calibrated values for the wages $\left(w_{o d}^{s}\right)$. Next, the total volume of remittances received by natives living in the origin country $o$ is assessed by summing the remittance flows across all destination countries:

$$
R E M I T_{o}=\sum_{d} R E M I T_{d o}
$$

In the origin countries, the total amount of remittances received is then split equally among the non-migrating nationals, independent of their skill level. The per worker amount, $\mathrm{rem}_{o}$, is then 
defined as:

$$
r e m_{o}=\frac{R E M I T_{o}}{\sum_{s=L, M, H} N_{d d}^{s}}
$$

Thus, the total income after remittances of a non-migrant in country $o$ of type $s$ is given by:

$$
\hat{w}_{o o}^{s}=w_{o o}^{s}+r e m_{o}
$$

where $w_{o o}^{s}$ is the skill-specific wage rate.

Note that Equation (33) can be adapted to account for skill-specific remitting behavior among emigrants. Assuming that emigrants of skill level $s 1$ remit $\alpha \%$ more than individuals of skill level $s 2$ or $s 3$ and rewriting Equation (33), we now have:

$$
R E M I T_{d o}=N_{o d}^{s 1} w_{o d}^{s 1}(1+\alpha) \eta_{o d}^{\prime}+\sum_{s=s 2, s 3} N_{o d}^{s} w_{o d}^{s} \eta_{o d}^{\prime}
$$

The fraction of income remitted in this case is

$$
\eta_{o d}^{\prime}=\frac{R E M I T_{d o}}{N_{o d}^{s 1} w_{o d}^{s 1}(1+\alpha)+\sum_{s=s 2, s 3} N_{o d}^{s} w_{o d}^{s}} .
$$

Once the fraction of income remitted is known, the same procedure as above applies for assessing the amount received by each non-migrant in the sending country. Note that if $\alpha>1-$ i.e. one type of individual remits more $-\tau_{o d}^{\prime}<\tau_{o d}$ (i.e. the individuals with a different education level remit a lower fraction of their income as compared to the benchmark case with equal remitting behavior).

Figure 15 displays the welfare effects under different assumptions about the propensity to remit for high- vs. low-skilled workers. As shown in the figure, the losses for the sending countries are smaller if we assume that high-skilled workers remit a larger share of their income.

\section{C.2 Brain Gain}

In Section 6.2, we include a brain gain mechanism in the model, allowing the share of high-skilled stayers to be an increasing function of the share of high-skilled emigrants. Here we explain the extension in greater detail.

Define $s h_{S}=\frac{H_{n}}{H_{n}+M_{n}+L_{n}}$ and $s h_{E}=\frac{H_{e}}{H_{e}+M_{e}+L_{e}}$, respectively, as the observed share of highskilled stayers and emigrants under the baseline scenario, and $\widehat{s h_{S}}$ and $\widehat{s h_{E}}$ as the equivalent shares under the counterfactual. We compute the new counterfactual share of high-skilled stayers as

$$
\widehat{s h_{S}}=s h_{S}\left(1+\sigma_{b} \frac{\widehat{s h_{E}}-s h_{E}}{s h_{E}}\right)
$$

Further, define the total number of stayers and emigrants in the counterfactual world as $\widehat{\text { Stay }}=$ $\widehat{H_{n}}+\widehat{M_{n}}+\widehat{L_{n}}$ and $\widehat{E m i g}=\widehat{H_{e}}+\widehat{M}_{e}+\widehat{L_{e}}$. The new share of high-skilled workers in the total population $\left(\widehat{s h_{N}}\right)$ is then:

$$
\widehat{s h_{N}}=\frac{\widehat{s h_{S}} \widehat{S t a y}+\widehat{s h_{E}} \widehat{E m i g}}{\widehat{S t a y}+\widehat{E m i g}}
$$

In the neutrally-selected world, the share of skilled workers among the emigrants, the stayers and the total population is equal. However, the skilled emigrants in the neutrally-selected 


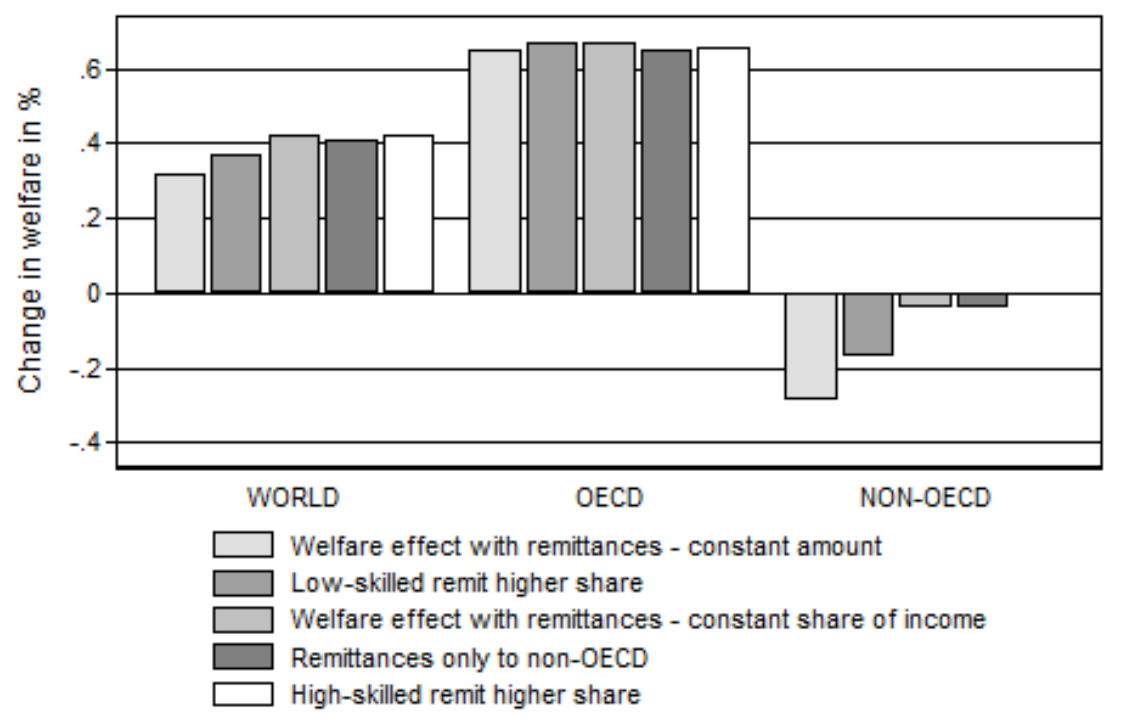

Figure 15: Welfare effects with a skill-dependent propensity to remit

Source: Own calculations.

Notes: This graph displays the welfare effects of the skill bias in migration with a skill-dependent propensity to remit. The vertical axis shows changes in welfare per never-migrant in percent.

world will induce a brain gain mechanism as the new share of skilled among emigrants becomes $\widehat{s h_{E}}=\widehat{s h_{N}}$. We therefore need to iterate on $\widehat{s h_{E}}$ until $\widehat{s h_{E}}=s h_{E}$. Thus, we first compute the share of skilled stayers using Equation (39). We save the value of the share of skilled emigrants used in the computation in order to replace it in the next iteration $\left(s h_{E}=\widehat{s h_{E}}\right)$. Based on this, we assess the new share of skilled natives $\widehat{s h_{N}}$ using Equation (40). Given that in a neutrallyselected world $\widehat{s h_{E}}=\widehat{s h_{N}}$, we use this value in the next iteration, by inserting it jointly with the value of $s h_{E}$ previously saved into Equation (39). Hence, we iterate on $s h_{E}$ until the new equilibrium share of skilled natives (and emigrants) is obtained (i.e. $s h_{S}=\widehat{s h_{S}}$ in Equation $(C .2)$ ). We can then assess the new skill distribution of the population. The total population and the number of emigrants does not change (by assumption) and the initial share of tertiaryeducated workers allows us to recover the number of educated workers in each population group (emigrants and stayers). The remaining workers are distributed between the medium- and lowskilled groups using the relative weight of the groups in our baseline counterfactual exercise, namely $s h_{M e d}=\frac{M e d}{M e d+L o w}$ for the medium-skilled and $s h_{\text {Low }}=\frac{\text { Low }}{\text { Med+Low }}$ for the low-skilled. Hence, the new shares of medium- and low-skilled workers become $\widehat{s h_{M e d}}=s h_{M e d}\left(1-\widehat{s h_{N}}\right)$ and $\widehat{s h_{\text {Low }}}=s h_{\text {Low }}\left(1-\widehat{s h_{N}}\right)$, respectively. Multiplying the total number of stayers and emigrants by these respective shares allows us to recover the full distribution of workers.

\section{C.3 Down-SKILling OF MigRANTS}

In Section 6.4, we accounted for down-skilling of immigrants in the receiving countries. In this section, we explain how we compute the down-skilling rates. We compute three down-skilling rates: the share of high-skilled migrants working in medium-skilled occupations, $d_{M, o}^{H}$, the share of high-skilled migrants in low-skilled occupations, $d_{L, o}^{H}$ and the share of medium-skilled migrants in low-skilled occupations, $d_{L, o}^{M}$. We assume each down-skilling rate to be specific to the sending 
country (index o), and we apply the same factor for all immigrants in the OECD for both the baseline and the counterfactual. We use sending-country-specific rather than country-pairspecific down-skilling rates, because many country-occupation-skill-specific immigrant numbers are zero or very small.

To compute the down-skilling rates for a given sending country, we use the OECD-DIOC data, which has information on the skill requirement for occupations at the ISCO one-digit level, as well as the skill distribution of immigrants within each occupation by sending country. For instance, we know how many high-skilled Senegalese are working in low-skilled occupations in France, Canada, the UK and all other OECD countries. Based on this information, we can compute the three down-skilling rates for every country pair, for example, $d_{M, o d}^{H}$. To compute the sending-country-specific down-skilling rates, we compute a weighted average over all receiving countries (index $d$ ),

$$
d_{M, o}^{H}=\sum_{d}\left(\frac{H_{o d}^{e m i g}}{H_{o}^{e m i g}}\right) d_{M, o d}^{H},
$$

with the weights $w_{o d}$ being the share of high-skilled emigrants in receiving country $d$ among all high-skilled emigrants from sending country $o$. The remaining down-skilling rates are computed analogously.

\section{Sensitivity CHECKS}

In Figure 15 panels (a)-(g), we perform a series of sensitivity checks with respect to the structural parameters. Overall, the results are both quantitatively and qualitatively robust to changes in parameters, although some parameters have a greater influence than others. The details are as follows:

- In panel (a), we vary the elasticity of substitution between varieties of $X$ and $Y$. A higher elasticity of substitution translates into a more pronounced market size effect, which leads to higher gains in the receiving and higher losses in the sending countries.

- In panel (b), we vary the elasticity of substitution between tradable and non-tradable goods. The results are very similar compared to the baseline results. A higher elasticity of substitution leads to a greater response in trade flows, and dampens the overall effect.

- In panel (c), we vary the elasticity of substitution between different education levels, $\sigma_{s}$. A low substitutability between high- and low-skilled workers has a particularly strong impact on the sending countries, because it becomes more difficult for low-skilled workers to replace high-skilled emigrants.

- In panel (d), we vary the elasticity of substitution between migrants and natives, $\sigma_{n}$. In the sending countries, this parameter only affects the overall welfare effect through trade, but the results hardly respond to changes in $\sigma_{n}$. In the receiving countries, the effects are larger when migrants and natives are closer substitutes, but the overall results do not change by a large amount.

- In panel (e), we vary the preference parameter for the output from the traditional sector. If this parameter is very low, the effects are smaller because a given change in consumption of $\mathrm{T}$ has a smaller impact on utility. 
- In panel (f), when we vary $\beta$, the relative preference for the tradable manufactured good, it turns out that the largest effect in the sending countries occurs if both goods receive equal weight, and the increase in market size is spread across both sectors, $X$ and $Y$. In the receiving countries, the welfare effect is almost unaffected by changes in $\beta$.

- In panel (g), we increase the fixed costs of entry by multiplying the original fixed costs with a factor 10 . The effects in the sending countries are stronger, because even fewer varieties are produced in the baseline compared to the counterfactual. 


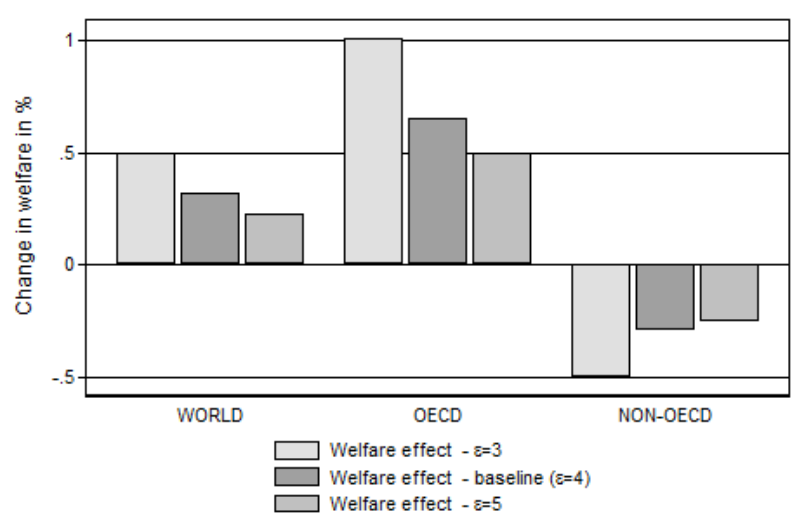

(a) Varying $\varepsilon$

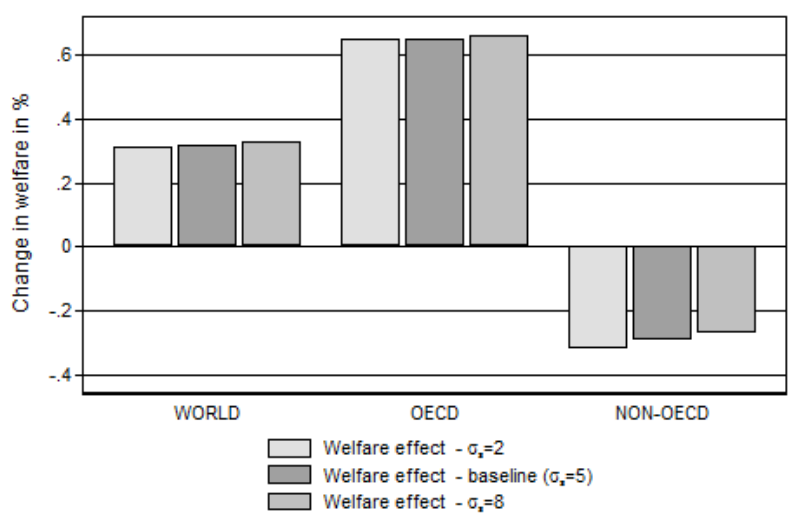

(c) Varying $\sigma_{s}$

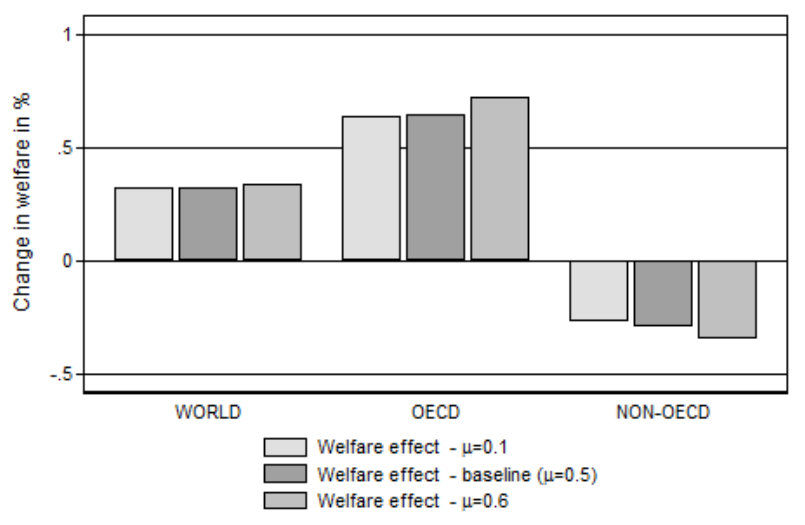

(e) Varying $\mu$

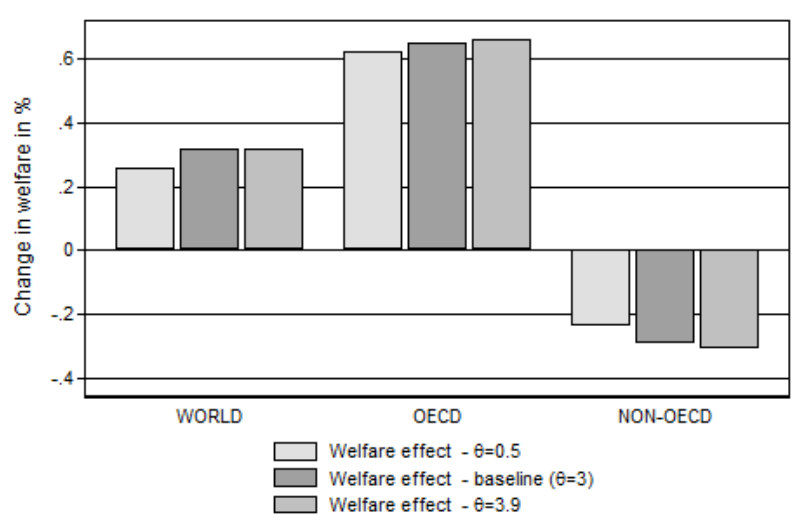

(b) Varying $\theta$

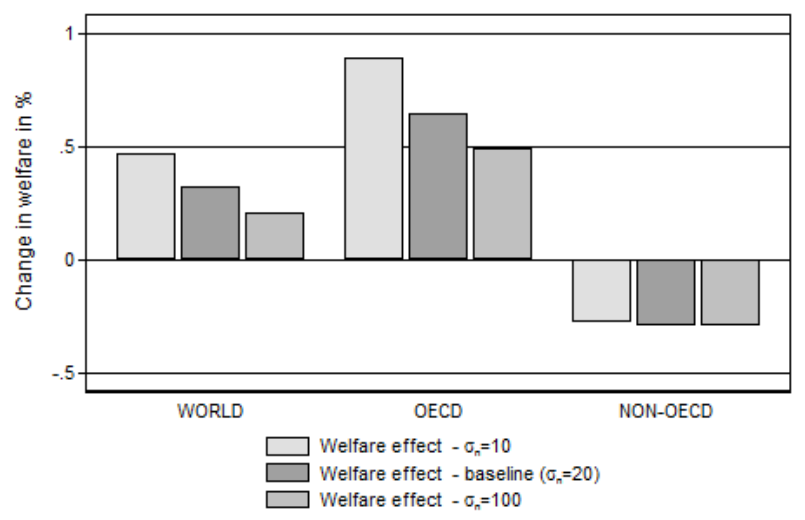

(d) Varying $\sigma_{n}$

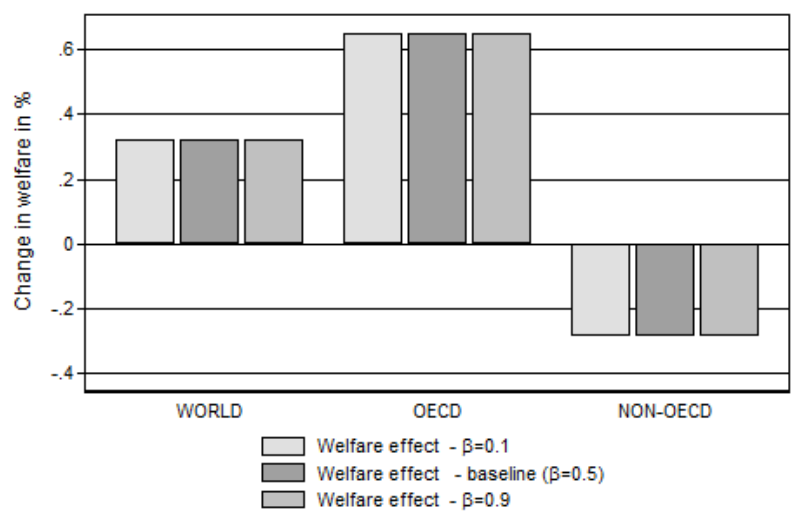

(f) Varying $\beta$ 


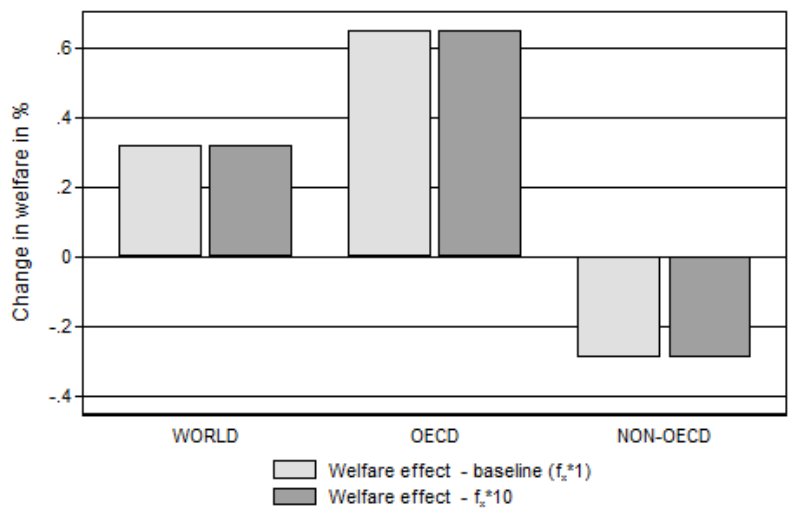

(g) Varying $f_{x}$

Figure 15: Sensitivity Checks

Source: Own calculations.

Notes: Panel (a) displays the welfare effects of the skill bias in migration with varying elasticity of substitution between differentiated goods, $\varepsilon \in\{3,4,5\}$. Panel (b) displays the welfare effects of the skill bias in migration with varying elasticity of substitution between tradable and non-tradable goods, $\theta \in\{2,3,3.9\}$. Panel (c) displays the welfare effects of the skill bias in migration with varying elasticity of substitution between education groups, $\sigma_{s} \in\{2,5,8\}$. Panel (d) displays the welfare effects of the skill bias in migration with varying elasticity of substitution between immigrants and natives, $\sigma_{n} \in\{10,20,100\}$. Panel (e) displays the welfare effects of the skill bias in migration with a varying preference parameter for the traditional good, $\mu \in\{0.1,0.5,0.6\}$. Panel (f) displays the welfare effects of the skill bias in migration with varying relative preference for the tradable good, $\beta \in\{0.1,0.5,0.9\}$. Panel (g) displays the welfare effects of the skill bias in migration with varying fixed costs of entry (baseline vs. fixed cost under baseline multiplied by 10). In all panels, the vertical axis shows changes in welfare per never-migrant in percent. 


\section{E List of abBReviations and Full Baseline Results}

Table 3: List of Country Abbreviations and Baseline Results

\begin{tabular}{|c|c|c|c|}
\hline$\overline{\text { Abbreviation }}$ & Country & Welfare per capita & Welfare per non-migrant \\
\hline \multicolumn{4}{|c|}{ Overall Average Effects } \\
\hline WORLD & World average & $1.43 \%$ & $0.32 \%$ \\
\hline OECD & OECD average & $2.54 \%$ & $0.65 \%$ \\
\hline NON-OECD & non-OECD average & $-0.83 \%$ & $-0.29 \%$ \\
\hline \multicolumn{4}{|c|}{ OECD countries } \\
\hline AUS & Australia & $4.82 \%$ & $1.35 \%$ \\
\hline AUT & Austria & $-0.01 \%$ & $0.01 \%$ \\
\hline BEL & Belgium & $0.32 \%$ & $0.12 \%$ \\
\hline $\mathrm{CAN}$ & Canada & $6.58 \%$ & $1.73 \%$ \\
\hline $\mathrm{CHE}$ & Switzerland & $4.81 \%$ & $1.03 \%$ \\
\hline CHL & Chile & $-0.03 \%$ & $0.02 \%$ \\
\hline $\mathrm{CZE}$ & Czech Republic & $-0.46 \%$ & $-0.08 \%$ \\
\hline DEU & Germany & $-0.61 \%$ & $-0.14 \%$ \\
\hline DNK & Denmark & $0.45 \%$ & $0.16 \%$ \\
\hline ESP & Spain & $0.54 \%$ & $0.16 \%$ \\
\hline EST & Estonia & $-0.50 \%$ & $-0.11 \%$ \\
\hline FIN & Finland & $-0.06 \%$ & $-0.02 \%$ \\
\hline FRA & France & $0.77 \%$ & $0.23 \%$ \\
\hline GBR & United Kingdom & $2.62 \%$ & $0.79 \%$ \\
\hline GRC & Greece & $0.56 \%$ & $0.19 \%$ \\
\hline HUN & Hungary & $-0.39 \%$ & $-0.06 \%$ \\
\hline IRL & Ireland & $1.20 \%$ & $0.46 \%$ \\
\hline ISL & Iceland & $-1.13 \%$ & $-0.37 \%$ \\
\hline ISR & Israel & $5.99 \%$ & $1.69 \%$ \\
\hline ITA & Italy & $-0.22 \%$ & $-0.05 \%$ \\
\hline JPN & Japan & $0.11 \%$ & $0.05 \%$ \\
\hline KOR & Korea, Rep. & $-0.40 \%$ & $-0.09 \%$ \\
\hline LUX & Luxembourg & $5.10 \%$ & $1.45 \%$ \\
\hline MEX & Mexico & $-0.06 \%$ & $-0.01 \%$ \\
\hline NLD & Netherlands & $0.97 \%$ & $0.29 \%$ \\
\hline NOR & Norway & $0.75 \%$ & $0.24 \%$ \\
\hline NZL & New Zealand & $1.54 \%$ & $0.44 \%$ \\
\hline POL & Poland & $-1.27 \%$ & $-0.32 \%$ \\
\hline PRT & Portugal & $0.95 \%$ & $0.24 \%$ \\
\hline SVK & Slovak Republic & $-1.49 \%$ & $-0.39 \%$ \\
\hline SVN & Slovenia & $0.56 \%$ & $0.15 \%$ \\
\hline SWE & Sweden & $0.80 \%$ & $0.25 \%$ \\
\hline TUR & Turkey & $-0.10 \%$ & $-0.05 \%$ \\
\hline USA & United States & $4.17 \%$ & $1.10 \%$ \\
\hline
\end{tabular}

NON-OECD countries 
Table 3 - continued from previous page

\begin{tabular}{|c|c|c|c|}
\hline Abbreviation & Country & Welfare per capita & Welfare per non-migrant \\
\hline AFG & Afghanistan & $-1.43 \%$ & $-0.68 \%$ \\
\hline ALB & Albania & $-2.70 \%$ & $-1.54 \%$ \\
\hline $\mathrm{ARE}$ & United Arab Emirates & $-0.33 \%$ & $-0.08 \%$ \\
\hline $\mathrm{ARG}$ & Argentina & $-1.40 \%$ & $-0.42 \%$ \\
\hline $\mathrm{ARM}$ & Armenia & $-2.37 \%$ & $-1.02 \%$ \\
\hline BDI & Burundi & $-1.72 \%$ & $-1.04 \%$ \\
\hline $\mathrm{BEN}$ & Benin & $-0.78 \%$ & $-0.42 \%$ \\
\hline BGD & Bangladesh & $-0.64 \%$ & $-0.22 \%$ \\
\hline BGR & Bulgaria & $0.13 \%$ & $0.06 \%$ \\
\hline BHR & Bahrain & $-1.26 \%$ & $-0.28 \%$ \\
\hline BLZ & Belize & $-10.68 \%$ & $-4.06 \%$ \\
\hline $\mathrm{BOL}$ & Bolivia & $-0.91 \%$ & $-0.35 \%$ \\
\hline BRA & Brazil & $-0.36 \%$ & $-0.10 \%$ \\
\hline $\mathrm{BRB}$ & Barbados & $-12.71 \%$ & $-5.24 \%$ \\
\hline $\mathrm{BRN}$ & Brunei Darussalam & $-1.46 \%$ & $-0.37 \%$ \\
\hline BWA & Botswana & $-0.73 \%$ & $-0.20 \%$ \\
\hline $\mathrm{CAF}$ & Central African Republic & $-2.64 \%$ & $-1.83 \%$ \\
\hline $\mathrm{CHN}$ & China & $-0.09 \%$ & $-0.02 \%$ \\
\hline CIV & Cote d'Ivoire & $-1.55 \%$ & $-0.61 \%$ \\
\hline CMR & Cameroon & $-2.84 \%$ & $-1.19 \%$ \\
\hline $\mathrm{COD}$ & Democratic Republic of the Congo & $-1.32 \%$ & $-0.59 \%$ \\
\hline $\mathrm{COG}$ & Congo & $-1.89 \%$ & $-0.47 \%$ \\
\hline $\mathrm{COL}$ & Colombia & $-1.34 \%$ & $-0.39 \%$ \\
\hline CRI & Costa Rica & $-0.85 \%$ & $-0.25 \%$ \\
\hline CUB & Cuba & $-4.71 \%$ & $-1.39 \%$ \\
\hline CYP & Cyprus & $-0.01 \%$ & $0.02 \%$ \\
\hline DOM & Dominican Republic & $-3.42 \%$ & $-1.04 \%$ \\
\hline $\mathrm{DZA}$ & Algeria & $-2.50 \%$ & $-0.70 \%$ \\
\hline $\mathrm{ECU}$ & Ecuador & $-2.58 \%$ & $-0.80 \%$ \\
\hline EGY & Egypt & $-0.76 \%$ & $-0.26 \%$ \\
\hline FJI & Fiji & $-4.32 \%$ & $-1.77 \%$ \\
\hline GAB & Gabon & $-2.40 \%$ & $-0.66 \%$ \\
\hline GHA & Ghana & $-2.37 \%$ & $-1.18 \%$ \\
\hline GMB & Gambia, The & $-4.03 \%$ & $-2.04 \%$ \\
\hline GTM & Guatemala & $-2.58 \%$ & $-1.23 \%$ \\
\hline GUY & Guyana & $-13.59 \%$ & $-8.93 \%$ \\
\hline HKG & Hong Kong SAR, China & $-2.10 \%$ & $-0.44 \%$ \\
\hline HND & Honduras & $-7.37 \%$ & $-2.25 \%$ \\
\hline HRV & Croatia & $0.68 \%$ & $0.21 \%$ \\
\hline HTI & Haiti & $-11.44 \%$ & $-6.03 \%$ \\
\hline IDN & Indonesia & $-0.07 \%$ & $-0.02 \%$ \\
\hline IND & India & $-0.97 \%$ & $-0.33 \%$ \\
\hline IRN & Iran & $-1.41 \%$ & $-0.46 \%$ \\
\hline
\end{tabular}


Table 3 - continued from previous page

\begin{tabular}{|c|c|c|c|}
\hline Abbreviation & Country & Welfare per capita & Welfare per non-migrant \\
\hline IRQ & Iraq & $-1.63 \%$ & $-0.52 \%$ \\
\hline JAM & Jamaica & $-12.90 \%$ & $-4.01 \%$ \\
\hline JOR & Jordan & $-1.35 \%$ & $-0.34 \%$ \\
\hline KAZ & Kazakhstan & $-0.55 \%$ & $-0.19 \%$ \\
\hline $\mathrm{KEN}$ & Kenya & $-3.93 \%$ & $-1.67 \%$ \\
\hline $\mathrm{KGZ}$ & Kyrgyz Republic & $-0.25 \%$ & $-0.10 \%$ \\
\hline KHM & Cambodia & $-1.48 \%$ & $-0.88 \%$ \\
\hline KWT & Kuwait & $-2.23 \%$ & $-0.58 \%$ \\
\hline $\mathrm{LAO}$ & Lao PDR & $-2.86 \%$ & $-1.96 \%$ \\
\hline LBR & Liberia & $-7.22 \%$ & $-4.03 \%$ \\
\hline LBY & Libya & $-0.67 \%$ & $-0.14 \%$ \\
\hline LKA & Sri Lanka & $-2.19 \%$ & $-0.73 \%$ \\
\hline LSO & Lesotho & $-0.39 \%$ & $-0.17 \%$ \\
\hline LTU & Lithuania & $-0.47 \%$ & $-0.08 \%$ \\
\hline LVA & Latvia & $-1.87 \%$ & $-0.50 \%$ \\
\hline MAC & Macao SAR, China & $-0.01 \%$ & $-0.01 \%$ \\
\hline MAR & Morocco & $-3.92 \%$ & $-1.37 \%$ \\
\hline MDA & Moldova & $-2.11 \%$ & $-0.74 \%$ \\
\hline MDV & Maldives & $-0.53 \%$ & $-0.15 \%$ \\
\hline MLI & Mali & $-1.07 \%$ & $-0.65 \%$ \\
\hline MLT & Malta & $-6.82 \%$ & $-1.71 \%$ \\
\hline MMR & Myanmar & $-0.37 \%$ & $-0.28 \%$ \\
\hline MNG & Mongolia & $-0.29 \%$ & $-0.11 \%$ \\
\hline MOZ & Mozambique & $-1.09 \%$ & $-0.54 \%$ \\
\hline MRT & Mauritania & $-1.02 \%$ & $-0.34 \%$ \\
\hline MUS & Mauritius & $-6.53 \%$ & $-2.06 \%$ \\
\hline MWI & Malawi & $-0.68 \%$ & $-0.34 \%$ \\
\hline MYS & Malaysia & $-0.54 \%$ & $-0.14 \%$ \\
\hline NAM & Namibia & $-1.05 \%$ & $-0.34 \%$ \\
\hline NER & Niger & $-0.15 \%$ & $-0.09 \%$ \\
\hline NIC & Nicaragua & $-6.52 \%$ & $-2.36 \%$ \\
\hline NPL & Nepal & $-1.72 \%$ & $-0.93 \%$ \\
\hline PAK & Pakistan & $-1.53 \%$ & $-0.62 \%$ \\
\hline PAN & Panama & $-2.91 \%$ & $-0.80 \%$ \\
\hline PER & Peru & $-1.35 \%$ & $-0.39 \%$ \\
\hline PHL & Philippines & $-1.40 \%$ & $-0.57 \%$ \\
\hline PNG & Papua New Guinea & $-0.87 \%$ & $-0.55 \%$ \\
\hline PRY & Paraguay & $-0.91 \%$ & $-0.36 \%$ \\
\hline QAT & Qatar & $-0.48 \%$ & $-0.08 \%$ \\
\hline $\mathrm{ROU}$ & Romania & $-1.31 \%$ & $-0.39 \%$ \\
\hline RUS & Russian Federation & $0.34 \%$ & $0.10 \%$ \\
\hline RWA & Rwanda & $-1.51 \%$ & $-0.79 \%$ \\
\hline SAU & Saudi Arabia & $-0.33 \%$ & $-0.05 \%$ \\
\hline
\end{tabular}


Table 3 - continued from previous page

\begin{tabular}{cccc}
\hline Abbreviation & Country & Welfare per capita & Welfare per non-migrant \\
\hline SDN & Sudan & $-0.76 \%$ & $-0.34 \%$ \\
SEN & Senegal & $-2.67 \%$ & $-1.02 \%$ \\
SGP & Singapore & $-0.49 \%$ & $-0.07 \%$ \\
SLE & Sierra Leone & $-8.31 \%$ & $-6.04 \%$ \\
SLV & El Salvador & $-3.22 \%$ & $-1.20 \%$ \\
SRB & Serbia & $0.22 \%$ & $0.10 \%$ \\
SWZ & Swaziland & $-1.24 \%$ & $-0.45 \%$ \\
SYR & Syrian Arab Republic & $-1.15 \%$ & $-0.42 \%$ \\
TGO & Togo & $-1.10 \%$ & $-0.57 \%$ \\
THA & Thailand & $-0.24 \%$ & $-0.06 \%$ \\
TJK & Tajikistan & $-0.19 \%$ & $-0.08 \%$ \\
TON & Tonga & $-3.56 \%$ & $-1.93 \%$ \\
TTO & Trinidad and Tobago & $-10.03 \%$ & $-2.68 \%$ \\
TUN & Tunisia & $-2.17 \%$ & $-0.61 \%$ \\
TWN & Taiwan & $-0.58 \%$ & $-0.19 \%$ \\
TZA & Tanzania & $-1.10 \%$ & $-0.56 \%$ \\
UGA & Uganda & $-1.47 \%$ & $-0.67 \%$ \\
UKR & Ukraine & $-0.05 \%$ & $-0.01 \%$ \\
URY & Uruguay & $-2.58 \%$ & $-0.80 \%$ \\
VEN & Venezuela & $-1.31 \%$ & $-0.39 \%$ \\
VNM & Vietnam & $-0.96 \%$ & $-0.36 \%$ \\
YEM & Yemen & $-0.37 \%$ & $-0.12 \%$ \\
ZAF & South Africa & $-2.48 \%$ & $-0.64 \%$ \\
ZMB & Zambia & $-1.35 \%$ & $-0.46 \%$ \\
ZWE & Zimbabwe & $-2.76 \%$ & $-1.19 \%$ \\
ROW & Rest of World & $-1.38 \%$ & $-0.59 \%$ \\
\hline & & & \\
& & & \\
\hline
\end{tabular}

